UNIVERSITY OF GOTHENBURG

SCHOOL OF BUSINESS, ECONOMICS AND LAW

\author{
WORKING PAPERS IN ECONOMICS
}

No 355

\title{
POSITIONAL CONCERNS IN AN OLG MODEL: OPTIMAL LABOR AND CAPITAL INCOME TAXATION
}

Thomas Aronsson and Olof Johansson-Stenman

April 2009

ISSN 1403-2473 (print)

ISSN 1403-2465 (online) 


\title{
POSITIONAL CONCERNS IN AN OLG MODEL: OPTIMAL LABOR AND CAPITAL INCOME TAXATION ${ }^{* *}$
}

\author{
Thomas Aronsson * and Olof Johansson-Stenman ${ }^{+}$
}

\begin{abstract}
This paper concerns optimal income taxation under asymmetric information in a two-type overlapping generations model, where people care about their relative consumption compared to others. The appearance of positional concerns affects the policy choices via two channels: (i) the size of the average degree of positionality and (ii) positionality differences between the (mimicked) low-ability type and the mimicker. Under plausible empirical estimates, the marginal labor income tax rates become substantially larger, and the absolute value of the marginal capital income tax rate implemented for the low-ability type becomes substantially smaller, compared to the conventional optimal income tax model. In addition to measures of reference consumption based on the average consumption, results for the cases of withingeneration and upward comparisons are also presented.
\end{abstract}

Keywords: Optimal income taxation, asymmetric information, relative consumption, status, positional goods.

JEL Classification: D62, H21, H23, H41.

\footnotetext{
** The authors would like to thank three very constructive anonymous referees, Sören Blomquist, Fredrik Carlsson, Tatiana Kornienko, Arthur Schram, Tomas Sjögren, and seminar participants at Helsinki Center of Economic Research, Stockholm University, Örebro University, and Tax Forum (held at Moss, Jelöya, Norway), as well as participants at a workshop on behavioral public economics in Innsbruck, for helpful comments and suggestions. Research grants from The European Science Foundation, The Bank of Sweden Tercentenary Foundation, The Swedish Council for Working Life and Social Research, and The National Tax Board are also gratefully acknowledged.

* Address: Department of Economics, Umeå University, SE - 90187 Umeå, Sweden. E-mail: Thomas.Aronsson@econ.umu.se

${ }^{+}$Address: Department of Economics, School of Business, Economics and Law, University of Gothenburg, SE 40530 Göteborg, Sweden. E-mail: Olof.Johansson@economics.gu.se
} 


\section{INTRODUCTION}

Since the late 1970s, literature dealing with public policy in economies where consumers have positional preferences, i.e., relative consumption concerns, has gradually developed. ${ }^{1}$ The importance of this literature has become more apparent over time, as corresponding empirical literature has grown. There is by now convincing empirical support for the idea that relative consumption comparisons are important from at least three independent economic sub-literatures: happiness research ${ }^{2}$ (e.g., Easterlin 2001; Blanchflower and Oswald 2005; Ferrer-i-Carbonell 2005; Luttmer 2005), questionnaire-based experiments ${ }^{3}$ (e.g., JohanssonStenman et al. 2002; Solnick and Hemenway 2005; Carlsson et al. 2007), and more recently from brain science (Fliessbach et al. 2007). There are also recent evolutionary models consistent with relative consumption concerns (Samuelson 2004; Rayo and Becker 2007).

Earlier studies on optimal taxation in economies where people make relative consumption comparisons often assume that the government uses linear tax instruments. Furthermore, almost all of them are based on static models, and have in common that they neglect capital income taxation. In the present paper, we consider an overlapping generations (OLG) model with two ability-types and asymmetric information between the private sector and the government (an extension of the two-type optimal income tax model developed by Stern 1982 and Stiglitz 1982). The set of tax instruments consists of nonlinear taxes on labor income and capital income. Therefore, the tax instruments considered here are based on informational limitations and not on any other a priori restrictions. The overall purpose is to analyze how the appearance of positional preferences modifies the optimal income tax

\footnotetext{
${ }^{1}$ Earlier studies address a variety of issues such as optimal taxation, public good provision, social insurance, growth, environmental externalities, and stabilization policy; see, e.g., Boskin and Sheshinski (1978), Layard (1980), Ng (1987), Tuomala (1990), Blomquist (1993), Corneo and Jeanne (1997, 2001), Ireland (2001), Brekke and Howarth (2002), Abel (2005), Aronsson and Johansson-Stenman (2008a), and Wendner and Goulder (2008). Clark et al. (2008) provide a good overview of both the empirical evidence and economic implications of relative consumption concerns.

2 Stevenson and Wolfers (2008) constitute a recent exception in the happiness literature, claiming that the role of relative income is overstated.

${ }^{3}$ There are also experimental results from the social preference literature suggesting that people dislike inequity generally and disadvantageous inequity in particular, which can be interpreted as concern about relative outcome; see, e.g., Fehr and Schmidt (1999) and Bolton and Ockefels (2000).
} 
structure by comparison with the outcome of the standard two-type OLG model where people only care about their absolute consumption levels.

Only a few earlier studies have dealt with optimal nonlinear taxation in economies where people have positional preferences. To our knowledge, the first was a paper by Oswald (1983), who assumes a continuous ability-distribution and that each individual compares his/her own consumption with a reference point; the latter is interpretable as reflecting either jealousy or altruism. Oswald shows that allowing for jealousy/altruism affects the optimal tax structure in a complex way, and that several standard results of optimal tax theory (such as zero marginal tax rates at the ends of the skill-distribution and that differentiated commodity taxes should not be used with certain forms of separable preferences) may no longer apply. Furthermore, the results show that if the utility function is separable in the measure of reference consumption, then the marginal tax rates are higher in an economy with predominantly jealous people and lower in an economy with predominately altruistic people compared with the standard model without social interaction. Tuomala (1990) uses a similar model where the utility of each individual depends negatively on the average consumption of others, and generalizes some findings by Oswald beyond additive separability. In addition, he provides numerical simulations showing, for instance, that the optimal marginal tax rates may be substantially higher when taking positional concerns into account. Ireland (2001) also uses a model with a continuous ability-distribution and nonlinear taxation of labor income. He assumes that individuals signal their social status positions, which in turn necessitates using resources that could otherwise have been used for beneficial consumption. This constitutes an incentive for the government to intervene, meaning (again) that social interaction justifies the use of distortionary taxation. Finally, Aronsson and Johansson-Stenman (2008a) analyze a static two-type model where agents value their own consumption both in absolute terms and relative to a measure of reference consumption (the average consumption in the economy as a whole). The results show, among other things, how the redistributive and corrective roles of income taxation may interact, due to possible differences between agents with respect to the degree of positionality.

The present paper is also related to a small - yet growing - literature dealing with redistribution under asymmetric information in dynamic economies. The seminal contribution here is a paper by Ordover and Phelps (1979). In a model with a continuum of ability-types, they show (among other things) that if leisure is separable from private consumption in terms 
of the utility function (so the marginal rate of substitution between present and future consumption does not depend on the leisure choice other than via income), then the marginal capital income tax rate should be zero for each ability-type. Pirttilä and Tuomala (2001), in a generalization of the model in Brett (1997), consider an OLG model with two ability-types. Their results show that production inefficiency at the second-best optimum (which is a consequence of the desire to relax the self-selection constraint) justifies capital income taxation, whereas the marginal labor income tax rates take the same general form as in Stiglitz (1982), i.e., a positive marginal labor income tax rate should be imposed on the lowability type and a negative marginal labor income tax rate on the high-ability type. A somewhat related argument for using capital income taxation is found by Aronsson et al. (2009); they show that the appearance of equilibrium unemployment may justify capital income taxation, as it implies intertemporal production inefficiency at the second-best optimum. Finally, Boadway et al. (2000) analyze nonlinear labor income taxation and proportional capital income taxation in a model where both ability and initial wealth are unobserved by the government. In their framework, the capital income tax is interpretable as an indirect instrument to tax wealth.

The present study makes (at least) two distinct contributions to the literature. First, we are able to consider capital income taxation. As far as we know, the only previous study that analyzes capital income taxation under relative consumption concerns is Abel (2005). He considers optimal capital income taxation in an OLG model where all consumers of a given generation are identical, and where a linear capital income tax constitutes the only tax instrument. ${ }^{4}$ The present paper, in contrast, analyzes the remaining role of capital income taxation when the labor income tax has been chosen in an optimal way. As earlier research indicates that the capital income tax might be a useful tool for relaxing the self-selection constraint, as noted above, a natural question is whether this tax is also useful for purposes of internalizing positional externalities. We show (for a special case) that under plausible empirical estimates regarding relative consumption concerns, the marginal capital income tax rate implemented for the low-ability type may be substantially smaller in absolute value than would be predicted by a model without positional concerns. In addition, the well-known

\footnotetext{
${ }^{4}$ In Abel's study, the tax revenues are returned lump-sum to the old generation. The model also contains a social security system (based on lump-sum payments) with its own budget.
} 
result of zero marginal capital income tax rates under leisure separability (Ordover and Phelps 1979) generalizes to our more general framework for a natural benchmark case.

Second, our paper recognizes - and incorporates into the analysis - the idea that each individual may compare himself/herself more with some people than with others, i.e., the appropriate measure of "reference consumption" at the individual level need not necessarily be based on the average consumption in the economy as a whole (which is the common assumption in earlier literature on public policy in economies where agents have positional preferences). For example, some evidence suggests that people compare themselves more with people who are similar to themselves (see Runciman 1966), whereas McBride (2001) found that people's well-being depends on their income relative to the income of people belonging to the same generation as themselves. Others, such as Veblen (1899), Duesenberry (1949), and Schor (1998), have argued for the importance of an asymmetry, such that "lowincome groups are affected by consumption of high-income groups but not vice versa” (Duesenberry 1949 p. 101). This is also consistent with the empirical findings of Bowles and Park (2005) that more inequality in society tends to imply longer work hours. Therefore, in addition to measures based on the average consumption in the economy as a whole (which is our reference case), we consider two alternative approaches for measuring reference consumption at the individual level: the average consumption among people in the same generation and the average consumption among high-ability individuals.

The outline of the study is as follows: Section 2 presents the model and the outcome of private optimization based on a model where each individual compares his/her consumption with the average consumption in that period. Section 3 characterizes the corresponding optimal tax problem of the government, whereas Sections 4 presents the optimal labor income and capital income taxation results in a format that aims to facilitate straightforward interpretations and comparisons with earlier literature. Section 5 presents results for alternative reference points: in subsection 5.1, we analyze the case where people solely make within-generation consumption comparisons, and in subsection 5.2 we analyze the case where the reference point solely depends on the consumption by high-ability individuals. Section 6 summarizes and concludes the paper, while proofs are presented in the appendix.

\section{POSITIONAL PREFERENCES, FIRMS, AND MARKET EQUILIBRIUM}




\subsection{The OLG framework and utility functions}

Consider an OLG model where each agent lives for two periods. Following the convention in earlier literature, we assume that each individual works during the first period of life and does not work during the second. There are two types of individuals, where the low-ability type (type 1) is less productive than the high-ability type (type 2). The number of individuals of ability-type $i$ who were born at the beginning of period $t$ is denoted $n_{t}^{i}$. Each such individual cares about his/her consumption when young and when old, $c_{t}^{i}$ and $x_{t+1}^{i}$, and his/her leisure when young, $z_{t}^{i}$, given by a time endowment, $H$, less the hours of work, $l_{t}^{i}$ (when old, all available time is leisure). In addition, as the agents are assumed to have positional preferences, they also compare their own consumption with a measure of reference consumption. We follow earlier comparable literature in assuming that the private consumption good (the consumption of which is denoted $c$ when young and $x$ when old) is in part a positional good, whereas leisure is completely non-positional. ${ }^{5}$

The preferences for relative consumption, or positional preferences, can of course still be modeled in many different ways. Here we follow the approach chosen by many earlier studies by letting the relative consumption be described by the difference between an individual's own consumption and the average consumption in the economy as a whole, given by $\bar{c}_{t}$ at time $t$; cf., e.g., Akerlof (1997), Corneo and Jeanne (1997), Ljungqvist and Uhlig (2000), Bowles and Park (2005), and Carlsson et al. (2007). ${ }^{6}$ The utility function of ability-type $i$ born in the beginning of period $t$ can then be written as

$$
U_{t}^{i}=v_{t}^{i}\left(c_{t}^{i}, z_{t}^{i}, x_{t+1}^{i}, c_{t}^{i}-\bar{c}_{t}, x_{t+1}^{i}-\bar{c}_{t+1}\right)=u_{t}^{i}\left(c_{t}^{i}, z_{t}^{i}, x_{t+1}^{i}, \bar{c}_{t}, \bar{c}_{t+1}\right)
$$

\footnotetext{
${ }^{5}$ As noted by Aronsson and Johansson-Stenman (2008a), it is of course possible to extend the analysis by allowing people to care about their relative amount of leisure. We leave this to future research. Our conjecture is that the major qualitative insights will still hold as long as private consumption is more positional than leisure, which is consistent with the limited empirical evidence (Solnick and Hemenway 1998, 2005; Carlsson et al. 2007).

${ }^{6}$ Alternative approaches include ratio comparisons (Boskin and Sheshinski 1978; Layard 1980; Abel 2005; Wendner and Goulder 2008) and comparisons of ordinal rank (Frank 1985; Hopkins and Kornienko 2004). Dupor and Liu (2003) consider a specific flexible functional form that includes the difference comparison and ratio comparison approaches as special cases.
} 
The utility function $v_{t}^{i}(\cdot)$ is increasing in each argument, implying that $u_{t}^{i}(\cdot)$ is decreasing in $\bar{c}_{t}$ and $\bar{c}_{t+1}$ and increasing in the other arguments. Both $v_{t}^{i}(\cdot)$ and $u_{t}^{i}(\cdot)$ are assumed to be twice continuously differentiable in their respective arguments and strictly concave. The level of reference consumption in period $t$ is measured by the average consumption among all people alive in this time period:

$$
\bar{c}_{t}=\frac{n_{t}^{1} c_{t}^{1}+n_{t}^{2} c_{t}^{2}+n_{t-1}^{1} x_{t}^{1}+n_{t-1}^{2} x_{t}^{2}}{N_{t}},
$$

in which $N_{t}=n_{t}^{1}+n_{t}^{2}+n_{t-1}^{1}+n_{t-1}^{2}$. This means that each individual compares his/her own consumption with the average consumption in each period. We also assume that each individual treats the reference levels, $\bar{c}_{t}$ and $\bar{c}_{t+1}$, as exogenous.

The utility function in equation (1) is quite general and may vary both between ability-types and across generations, and is furthermore not necessarily time-separable, meaning for example that the marginal rate of substitution between relative and absolute consumption when old is not necessarily independent of the consumption level when young. Thus, the model is flexible enough to encompass habit formation in private consumption. We will perform much of the analysis by using the second - and more general - utility formulation in equation (1), i.e., the function $u_{t}^{i}(\cdot)$. This case resembles a classical externality problem, e.g., in terms of pollution associated with private consumption. However, we will need the first utility formulation based on the function $v_{t}^{i}(\cdot)$ when we relate the optimal tax policy to the extent that people care about relative consumption. The definition of such measures is the issue to which we turn next.

\subsection{The degree of consumption positionality}

Since much of the subsequent analysis is focused on relative consumption concerns, it is useful to introduce measures of the degree to which such concerns matter for each individual. By defining $\Delta_{t}^{i, c}=c_{t}^{i}-\bar{c}_{t}$ and $\Delta_{t+1}^{i, x}=x_{t+1}^{i}-\bar{c}_{t+1}$, we can rewrite the first part of equation (1) as

$$
U_{t}^{i}=v_{t}^{i}\left(c_{t}^{i}, z_{t}^{i}, x_{t+1}^{i}, \Delta_{t}^{i, c}, \Delta_{t+1}^{i, x}\right) .
$$


We can then define the degree of consumption positionality (cf., e.g., Johansson-Stenman et al. 2002; Aronsson and Johansson-Stenman 2008a) when young and old, respectively, based on the utility function in equation (1) as follows:

$$
\begin{aligned}
& \alpha_{t}^{i, c}=\frac{v_{t, \Delta_{t}^{c}}^{i}}{v_{t, \Delta_{t}^{c}}^{i}+v_{t, c}^{i}}, \\
& \alpha_{t+1}^{i, x}=\frac{v_{t, \Delta_{t+1}^{x}}^{i}}{v_{t, \Delta_{t+1}^{x}}^{i}+v_{t, x}^{i}},
\end{aligned}
$$

where $v_{t, c}^{i} \equiv \partial v_{t}^{i} / \partial c_{t}^{i}$ and similarly for the other variables. The term $\alpha_{t}^{i, c}$ can then be interpreted as the fraction of the overall utility increase from the last dollar spent in period $t$, i.e. when young, that is due to the increased relative consumption. For instance, if $\alpha_{t}^{i, c}$ approaches zero, then relative consumption does not matter on the margin, whereas in the other extreme case where $\alpha_{t}^{i, c}$ approaches one, absolute consumption does not matter (i.e., all that matters is relative consumption). The interpretation of $\alpha_{t+1}^{i, x}$ is analogous except that this term reflects the degree of consumption positionality when old instead of when young. From the assumptions about the utility functions, we have $0<\alpha_{t}^{i, c}, \alpha_{t+1}^{i, x}<1$. In addition, let us denote the average degree of consumption positionality in period $t$ :

$$
\bar{\alpha}_{t}=\sum_{i} \alpha_{t}^{i, x} \frac{n_{t-1}^{i}}{N_{t}}+\sum_{i} \alpha_{t}^{i, c} \frac{n_{t}^{i}}{N_{t}} \in(0,1)
$$

In other words, $\bar{\alpha}_{t}$ reflects the average value of the degree of consumption positionality among the people alive in period $t$.

\subsection{Individual optimization and market equilibrium}

The individual budget constraint is given by $^{7}$

\footnotetext{
${ }^{7}$ As our model does not distinguish between different types of commodities, we abstract from commodity taxation throughout the paper. This approach has also been taken in most earlier comparable literature (see Introduction). This does not reflect a belief that commodity taxation is unimportant in connection to positional preferences. However, there are several practical problems associated with such extensions. For example,
} 


$$
\begin{aligned}
& w_{t}^{i} l_{t}^{i}-T_{t}\left(w_{t}^{i} l_{t}^{i}\right)-s_{t}^{i}=c_{t}^{i}, \\
& s_{t}^{i}\left(1+r_{t+1}\right)-\Phi_{t+1}\left(s_{t}^{i} r_{t+1}\right)=x_{t+1}^{i},
\end{aligned}
$$

where $s_{t}^{i}$ is savings, $r_{t+1}$ is the market interest rate, and $T_{t}(\cdot)$ and $\Phi_{t+1}(\cdot)$ denote the payments of labor income and capital income taxes, respectively. The first order conditions for the hours of work and savings can be written as

$$
\begin{aligned}
& u_{t, c}^{i} w_{t}^{i}\left[1-T_{t}^{\prime}\left(w_{t}^{i} l_{t}^{i}\right)\right]-u_{t, z}^{i}=0, \\
& -u_{t, c}^{i}+u_{t, x}^{i}\left[1+r_{t+1}\left[1-\Phi_{t+1}^{\prime}\left(s_{t}^{i} r_{t+1}\right)\right]\right]=0,
\end{aligned}
$$

in which $u_{t, c}^{i}=\partial u_{t}^{i} / \partial c_{t}^{i}, u_{t, z}^{i}=\partial u_{t}^{i} / \partial z_{t}^{i}$, and $u_{t, x}^{i}=\partial u_{t}^{i} / \partial x_{t+1}^{i}$, while $T_{t}^{\prime}\left(w_{t}^{i} l_{t}^{i}\right)$ and $\Phi_{t+1}^{\prime}\left(s_{t}^{i} r_{t+1}\right)$ are the marginal labor income tax rate and the marginal capital income tax rate, respectively.

The production sector consists of identical competitive firms producing a homogenous good with constant returns to scale. Given these characteristics, the number of firms is not important and will be normalized to one for notational convenience. The production function is given by

$$
F\left(L_{t}^{1}, L_{t}^{2}, K_{t} ; t\right)=g\left(\theta^{1} L_{t}^{1}+\theta^{2} L_{t}^{2}, K_{t} ; t\right),
$$

where $L_{t}^{i}=n_{t}^{i} l_{t}^{i}$ is the total number of hours of work supplied by ability-type $i$ in period $t$, and $K_{t}$ is the capital stock in period $t ; \theta^{1}$ and $\theta^{2}$ are positive constants. The direct timedependency implies that we allow for exogenous technological change, i.e., productivity improvements. The firm obeys the necessary optimality conditions

$$
F_{L^{i}}\left(L_{t}^{1}, L_{t}^{2}, K_{t} ; t\right)=\frac{\partial g}{\partial\left(\theta^{1} L_{t}^{1}+\theta^{2} L_{t}^{2}\right)} \theta^{i}=w_{t}^{i} \quad \text { for } i=1,2 \text {, }
$$

different variants of the same group of commodities, such as cars, may be characterized by very different degrees of positionality. Moreover, the theoretical analysis would become considerably more complex, suggesting that commodity taxation warrants a paper of its own. 


$$
F_{K}\left(L_{t}^{1}, L_{t}^{2}, K_{t} ; t\right)=\frac{\partial g}{\partial K_{t}}=r_{t}
$$

Equation (9), for $i=1,2$, implies that the wage ratio, i.e., relative wage rate, is constant both within each period and over time (see below). ${ }^{8}$

\section{THE GOVERNMENT’S DECISION PROBLEM}

\subsection{Objective and constraints}

We assume that the government faces a general social welfare function as follows:

$$
W=W\left(n_{0}^{1} U_{0}^{1}, n_{0}^{2} U_{0}^{2}, n_{1}^{1} U_{1}^{1}, n_{1}^{2} U_{1}^{2}, \ldots .\right)
$$

which is increasing in each argument. Since the optimum conditions are expressed for any such social welfare function, they are necessary optimum conditions for a Pareto efficient allocation. ${ }^{9}$ A similar formulation is used by Pirttilä and Tuomala (2001), although they in addition assume that the social welfare function is utilitarian within each generation.

The informational assumptions are conventional. The government is able to observe income, although ability is private information. As in most earlier literature on the self-selection approach to optimal taxation, we assume that the government wants to redistribute from the high-ability to the low-ability type. ${ }^{10}$ This means that the most interesting aspect of selfselection is to prevent the high-ability type from pretending to be a low-ability type. The selfselection constraint that may bind then becomes

\footnotetext{
${ }^{8}$ This simplifying assumption is made solely for analytical convenience, as endogenous relative wage rates are not particularly important for the qualitative results derived below (i.e., for how the appearance of positional preferences affects the optimal marginal labor income and capital income tax rates). Readers interested in the more general case with endogenous relative wage rates are referred to the background working paper by Aronsson and Johansson-Stenman (2008b).

${ }^{9}$ All results obtained here that are independent of the social welfare function (i.e., basically all results that we comment on) could have been obtained by instead explicitly solving for the Pareto efficient allocation by maximizing the utility of one ability-type born in a certain period while holding the utility constant for all other agents (the other ability-type born in the same period and both ability-types born in all other periods). The chosen strategy is motivated by convenience, as it simplifies the presentation.

${ }^{10}$ This of course implies restrictions on the social welfare function beyond what is stated above.
} 


$$
U_{t}^{2}=u_{t}^{2}\left(c_{t}^{2}, z_{t}^{2}, x_{t+1}^{2}, \bar{c}_{t}, \bar{c}_{t+1}\right) \geq u_{t}^{2}\left(c_{t}^{1}, H-\phi l_{t}^{1}, x_{t+1}^{1}, \bar{c}_{t}, \bar{c}_{t+1}\right)=\hat{U}_{t}^{2}
$$

where $\phi=w_{t}^{1} / w_{t}^{2}=\theta^{1} / \theta^{2}$ is the wage ratio, which is a constant by the assumptions made earlier. The expression on the right-hand side of the weak inequality in (12) is the utility of the mimicker. Although the mimicker enjoys the same consumption as the low-ability type in each period, he/she enjoys more leisure (as the mimicker is more productive than the lowability type). ${ }^{11}$

Note that $T_{t}(\cdot)$ is a general labor income tax, which can be used to implement any desired combination of $l_{t}^{1}, c_{t}^{1}, l_{t}^{2}$, and $c_{t}^{2}$, given the savings chosen by each ability-type. Therefore, we will use $l_{t}^{1}, c_{t}^{1}, l_{t}^{2}$, and $c_{t}^{2}$, instead of the parameters of the labor income tax function, as direct decision variables in the optimal tax problem. Note also that the general capital income tax, $\Phi_{t+1}(\cdot)$, can be used to implement any desired combination of $c_{t}^{1}, x_{t+1}^{1}, c_{t}^{2}, x_{t+1}^{2}$, and $K_{t+1}$, given the labor income of each individual. Therefore, instead of choosing the parameters of the capital income tax function directly, we formulate the optimization problem such that $x_{t+1}^{1}, x_{t+1}^{2}$, and $K_{t+1}$ are also used as direct decision variables. The resource constraint is given by

$$
F\left(L_{t}^{1}, L_{t}^{2}, K_{t} ; t\right)+K_{t}-\sum_{i=1}^{2}\left[n_{t}^{i} c_{t}^{i}+n_{t-1}^{i} x_{t}^{i}\right]-K_{t+1}=0
$$

Equation (13) means that output is used for private consumption and net investments. Equations (12) and (13) together constitute the set of restrictions facing the government. The Lagrangean can then be written as

\footnotetext{
${ }^{11}$ Given the set of available policy instruments in our framework, it is possible for the government to control the present and future consumption as well as the hours of work of each ability-type (this is discussed more thoroughly below). As a consequence, in order to be a mimicker, the high-ability type must mimic the point chosen by the low-ability type on each tax function (both the labor income tax and the capital income tax), and thus consume equally much in both periods.
} 


$$
\begin{aligned}
& \mathcal{L}=W\left(n_{0}^{1} U_{0}^{1}, n_{0}^{2} U_{0}^{2}, n_{1}^{1} U_{1}^{1}, n_{1}^{2} U_{1}^{2}, \ldots .\right)+\sum_{t} \lambda_{t}\left[U_{t}^{2}-\hat{U}_{t}^{2}\right] \\
& +\sum_{t} \gamma_{t}\left[F\left(L_{t}^{1}, L_{t}^{2}, K_{t} ; t\right)+K_{t}-\sum_{i=1}^{2}\left[n_{t}^{i} c_{t}^{i}+n_{t-1}^{i} x_{t}^{i}\right]-K_{t+1}\right]
\end{aligned}
$$

For further use, let $\hat{u}_{t}^{2}=u_{t}^{2}\left(c_{t}^{1}, H-\phi l_{t}^{1}, x_{t+1}^{1}, \bar{c}_{t}, \bar{c}_{t+1}\right)$ denote the utility of the mimicker based on the second utility formulation in equation (1). As the decision-problem facing the government is written, ${ }^{12}$ the direct decision-variables relevant for generation $t$ are $l_{t}^{1}, c_{t}^{1}, x_{t+1}^{1}$, $l_{t}^{2}, c_{t}^{2}, x_{t+1}^{2}, K_{t}$, and $K_{t+1}$. The first-order conditions are presented in the appendix.

\subsection{The positionality effect}

Let us now turn to the welfare effect of an increase in the reference consumption, which will play a key role for marginal income taxation. The derivative of the Lagrangean with respect to $\overline{c_{t}}$ can be written as

(15) $\frac{\partial \mathcal{L}}{\partial \bar{c}_{t}}=\sum_{i=1}^{2} \frac{\partial W}{\partial\left(n_{t-1}^{i} U_{t-1}^{i}\right)} n_{t-1}^{i} u_{t-1, \bar{c}_{t}}^{i}+\sum_{i=1}^{2} \frac{\partial W}{\partial\left(n_{t}^{i} U_{t}^{i}\right)} n_{t}^{i} u_{t, \bar{c}_{t}}^{i}+\lambda_{t-1}\left[u_{t-1, \bar{c}_{t}}^{2}-\hat{u}_{t-1, \bar{c}_{t}}^{2}\right]+\lambda_{t}\left[u_{t, \bar{c}_{t}}^{2}-\hat{u}_{t, \bar{c}_{t}}^{2}\right]$.

We will refer to this derivative as measuring the positionality effect in period $t$, since it reflects the overall welfare effects of a change in the level of reference consumption in period $t$, ceteris paribus. By using the first utility formulation in equation (1), i.e., the function $v_{t}^{i}(\cdot)$, this effect can be rewritten in terms of the individual degrees of consumption positionality. Let us use the short notation

$$
\Gamma_{t}=\frac{\lambda_{t-1} \hat{u}_{t-t, x}^{2}}{\gamma_{t} N_{t}}\left[\hat{\alpha}_{t}^{2, x}-\alpha_{t}^{1, x}\right]+\frac{\lambda_{t} \hat{u}_{t, c}^{2}}{\gamma_{t} N_{t}}\left[\hat{\alpha}_{t}^{2, c}-\alpha_{t}^{1, c}\right]
$$

for the positionality differences between the mimicker and the low-ability type (measured for both generations alive in period $t$ ), where $\Gamma_{t}>0(<0)$ if the mimicker is always, i.e., as both

\footnotetext{
${ }^{12}$ Note that there is a potential time inconsistency problem involved here since the government may have incentives to modify the second period taxation facing each generation once the individuals have revealed their true types. Although we acknowledge this potential problem, we follow earlier comparable literature by only considering situations where the government commits to its tax policy. This is motivated by the observation that lack of commitment from the point of view of the government opens a spectrum of possibilities for modeling both public policy and the response by the private sector, which would be beyond the scope of this paper.
} 
young and old, more (less) positional than the low-ability type. We can then derive the following result:

Lemma 1. The welfare effect of increased reference consumption in period $t$ can be written as

$$
\frac{\partial \mathcal{L}}{\partial \bar{c}_{t}}=N_{t} \gamma_{t} \frac{\Gamma_{t}-\bar{\alpha}_{t}}{1-\bar{\alpha}_{t}}=-\frac{\bar{\alpha}_{t} \gamma_{t} N_{t}}{1-\bar{\alpha}_{t}}+\frac{1}{1-\bar{\alpha}_{t}}\left[\lambda_{t-1} \hat{u}_{t-1, x}^{2}\left[\hat{\alpha}_{t}^{2, x}-\alpha_{t}^{1, x}\right]+\lambda_{t} \hat{u}_{t, c}^{2}\left[\hat{\alpha}_{t}^{2, c}-\alpha_{t}^{1, c}\right]\right]
$$

Therefore, increased reference consumption in period treduces the welfare, so $\partial \mathcal{L} / \partial \bar{c}_{t}<0$, if and only if $\Gamma_{t}<\bar{\alpha}_{t}$. A sufficient condition for this to hold is that $\alpha_{t}^{1, c} \geq \hat{\alpha}_{t}^{2, c}$ and $\alpha_{t}^{1, x} \geq \hat{\alpha}_{t}^{2, x}$, meaning that the young and old low-ability type, respectively, is at least as positional as the corresponding mimicker in period $t$.

Two mechanisms are worth noticing. First, in the absence of the self-selection constraint, i.e., if ability-type specific lump-sum taxes were possible to implement, an increase in the reference consumption would unambiguously decrease the welfare, since the reference consumption enters the utility function of each individual via the arguments $\Delta_{t}^{i, c}=c_{t}^{i}-\overline{c_{t}}$ and $\Delta_{t+1}^{i, x}=x_{t+1}^{i}-\bar{c}_{t+1}$. Thus, the reference consumption constitutes a negative externality for each ability-type in each period. This explains the term proportional to $\bar{\alpha}_{t}$ in equation (16), which relates the positionality effect to the average degree of positionality without any reference to differences in the degree of positionality between ability-types. Second, if the low-ability type is more positional than the mimicker in both generations alive in period $t$ (i.e., generations $t$ and $t-1$ ), then an increase in the reference consumption means a larger utility loss for the low-ability type than for the mimicker; as such, it contributes to an additional welfare loss via the self-selection constraint. However, if the mimicker is more positional than the low-ability type, then an increase in the reference consumption contributes to relax the self-selection constraint, implying that $\Gamma_{t}>0$ in equation (16); this mechanism will be discussed in more detail subsequently. In this case, the sign of $\partial \mathcal{L} / \partial \bar{c}_{t}$ can be either positive or negative depending on whether or not $\Gamma_{t}<\bar{\alpha}_{t}$.

\section{RESULTS}


In this section, we present the optimality conditions for the marginal labor income tax rates and the marginal capital income tax rates in a format that facilitates straightforward economic interpretations, as well as comparisons with the standard optimal income tax model in which relative consumption concerns are absent. Note that the expressions for the marginal income tax rates presented below are valid in each time period along the general equilibrium path, i.e., for all $t$. The reason is, of course, that the second best optimal resource allocation means that the first order conditions used to derive these expressions are fulfilled in each time period. Moreover, the formulas for marginal income taxation hold irrespective of the sign and magnitude of individual responses to a change in the reference consumption. In other words, they hold irrespective of whether or not individual consumption increases as a result of an increase in the average consumption (or reference consumption more generally) in the same period, i.e., irrespective of whether there is in this sense a "keeping-up-with-the-Joneses consumption effect” and, therefore, also irrespective of whether such possible effects are small or large. ${ }^{13}$

\subsection{Labor Income Taxation}

By defining the marginal rate of substitution between leisure and private consumption for ability-type $i$ as

$$
M R S_{z, c}^{i, t}=\frac{u_{t, z}^{i}}{u_{t, c}^{i}},
$$

and similarly for the mimicker, we obtain the following expressions for the marginal labor income tax rates by using the government's first order conditions for $l_{t}^{1}, c_{t}^{1}, l_{t}^{2}$, and $c_{t}^{2}$ together with equation (6):

$$
\begin{aligned}
& T_{t}^{\prime}\left(w_{t}^{1} l_{t}^{1}\right)=\frac{\lambda_{t}^{*}}{w_{t}^{1} n_{t}^{1}}\left[M R S_{z, c}^{1, t}-\phi M \hat{R} S_{z, c}^{2, t}\right]-\frac{M R S_{z, c}^{1, t}}{\gamma_{t} w_{t}^{1} N_{t}} \frac{\partial \mathcal{L}}{\partial \bar{c}_{t}}, \\
& T_{t}^{\prime}\left(w_{t}^{2} l_{t}^{2}\right)=-\frac{M R S_{z, c}^{2, t}}{\gamma_{t} w_{t}^{2} N_{t}} \frac{\partial \mathcal{L}}{\partial \bar{c}_{t}},
\end{aligned}
$$

\footnotetext{
${ }^{13}$ See for example Arrow and Dasgupta (in press) for some theoretical analysis of such effects in an intertemporal model.
} 
where $\lambda_{t}^{*}=\lambda_{t} \hat{u}_{t, c}^{2} / \gamma_{t}$. The marginal labor income tax rates in equations (17) and (18) are straightforward extensions of the results derived in a static model by Aronsson and Johansson-Stenman (2008a). However, the present model is more general in the sense of capturing that a change in the reference consumption in period $t$, induced by a change in the hours of work supplied by the young generation, will affect the well-being of both the young and the old generation in that period. This will be discussed more thoroughly below.

The first term of equation (17) is analogous to results derived in earlier literature and is due to the self-selection constraint. With $M R S_{z, c}^{1, t}>M \hat{R} S_{z, c}^{2, t}$ (which applies if the preferences do not differ between ability-types), the contribution of the self-selection constraint is to increase the marginal labor income tax rate of the low-ability type; this effect is well understood from earlier research (Stiglitz 1982).

The final part of each formula reflects the relative consumption concerns. By combining Lemma 1 with equations (17) and (18), we obtain the following result:

Proposition 1. If the young and old low-ability type, respectively, is at least as positional as the corresponding mimicker in period $t$, or if the positionality differences are sufficiently small so that $\Gamma_{t}<\bar{\alpha}_{t}$, then the positionality effect contributes to increase the marginal labor income tax rate facing each ability-type in period $t$, ceteris paribus.

Note that the positionality effect discussed in Proposition 1 contains two parts: an externalitycorrecting component and a component that serves to relax the self-selection constraint. To see this more clearly, we will combine equations (16), (17), and (18) in order to decompose the positionality effect. Let us use the short notations $\sigma_{t}^{1}$ and $\sigma_{t}^{2}$ for the optimal marginal labor income tax rates without relative consumption concerns, where

$$
\sigma_{t}^{1}=\frac{\lambda_{t}^{*}}{w_{t}^{1} n_{t}^{1}}\left[M R S_{z, c}^{1, t}-\phi M \hat{R} S_{z, c}^{2, t}\right] \text { and } \sigma_{t}^{2}=0 .
$$

We can then rewrite the formulas for the marginal labor income tax rates such that the contribution of positionality is decomposed into two effects as follows: 
Proposition 2. The optimal marginal labor income tax rate for each ability-type can be written in the following additive form (for $i=1,2)$ :

$$
T_{t}^{\prime}\left(w_{t}^{i} l_{t}^{i}\right)=\sigma_{t}^{i}+\left[1-\sigma_{t}^{i}\right] \bar{\alpha}_{t}-\left[1-\sigma_{t}^{i}\right]\left[1-\bar{\alpha}_{t}\right] \frac{\Gamma_{t}}{1-\Gamma_{t}} .
$$

Equation (19) is an intertemporal analogue to (and has the same general interpretation as) a corresponding tax formula derived by Aronsson and Johansson-Stenman (2008a) in a static model; the difference is that $\bar{\alpha}_{t}$ and $\Gamma_{t}$ here reflect the preferences of both generations alive in period $t$. The intuition is that the young generation, which is the only generation working and paying labor income taxes, also imposes positional externalities on the old generation. The necessary additional correction (to internalize the positional externality that the young generation imposes on the old) is, therefore, part of the marginal labor income tax rates.

To interpret equation (19), note first that in the special case where the resource allocation is first best, meaning that $\lambda_{t}=0$ for all $t$, we have $\sigma_{t}^{1}=\sigma_{t}^{2}=\Gamma_{t}=0$, so $T_{t}^{\prime}\left(w_{t}^{1} l_{t}^{1}\right)=T_{t}^{\prime}\left(w_{t}^{2} l_{t}^{2}\right)=\bar{\alpha}_{t}$, which exemplifies a straightforward Pigouvian tax. The interpretation is that each individual is taxed for the negative positional externality that he/she imposes on other people.

Returning to our more general second-best model, the intuition is straightforward. The first term on the right-hand side of equation (19) is the tax expression that would follow without any positional concern. The second term measures the marginal external cost of consumption - as reflected by the average degree of positionality - although its contribution to the marginal labor income tax rates is modified by comparison with the first-best. Increased private consumption, associated with an increase in hours of work, causes negative external costs here as well; for the low-ability type, however, these external costs are smaller than in the first-best provided that $\sigma_{t}^{1}>0$ (which is the case we discussed above). The intuition is that the fraction of an income increase that is already taxed away does not give rise to positional externalities.

The third term on the right-hand side of equation (19) reflects self-selection effects of positional concerns. Suppose first that $\Gamma_{t}>0$, in which case the mimicker is more positional than the low-ability type. This means that increased reference consumption gives rise to a 
larger utility loss for the mimicker than it does for the low-ability type. Therefore, the government may relax the self-selection constraint by implementing policies that lead to increased reference consumption. This provides an incentive for the government to implement a lower marginal labor income tax rate than it would otherwise have done, which means that the third term contributes to decrease the marginal labor income tax rate. Consequently, if $\Gamma_{t}$ is positive and sufficiently large, then this effect may (at least theoretically) dominate the externality-correcting component, implying that relative consumption concerns contribute to reduce the marginal labor income tax rates. If on the other hand $\Gamma_{t}<0$, then the opposite argument applies. The latter case also explains in greater detail why the positionality effect unambiguously contributes to increase the marginal labor income tax rates if the young and old low-ability type, respectively, is at least as positional as the corresponding mimicker.

Let us briefly discuss how the appearance of positional preferences may affect the marginal labor income tax rates according to the empirical evidence. Consider first the high-ability type for which $\sigma_{t}^{2}=0$, and suppose also that $\Gamma_{t}=0$. The latter is motivated by the lack of empirical evidence of how the degree of positionaility varies with leisure, for a given consumption level (remember that the mimicker and the low-ability type have the same consumption levels). In this case, the optimal tax is equal to $\bar{\alpha}_{t}$ for the high-ability type. According to the survey-experimental evidence of Alpizar et al. (2005) and Carlsson et al. (2007), $\bar{\alpha}_{t}$ is in the order of magnitude of 0.5. Wendner and Goulder (2008) provide a rigorous treatment of existing survey-experimental evidence (see their Table 1, p. 1978), where they apply the same statistical methods to different data sets. They conclude that the evidence taken together suggests that $\bar{\alpha}_{t}$ should be between 0.2 and 0.4 . On the other hand, $\bar{\alpha}_{t}=0.8$ would be more in line with the evidence based on the happiness studies of Easterlin (1995) and Luttmer (2005). These are clearly very dramatic differences compared to the zero marginal tax rate that would apply in the absence of positional preferences. For the lowability type, the same assumptions would imply corresponding effects, although the changes in relative terms would seem less dramatic, since the pure self-selection component, $\sigma_{t}^{1}$, is most likely positive (see above and Stiglitz 1982).

\subsection{Capital Income Taxation}


Let us now turn to the marginal capital income tax structure. Define the marginal rate of substitution between consumption in periods $t$ and $t+1$ for ability-type $i$

$$
M R S_{c, x}^{i, t}=\frac{u_{t, c}^{i}}{u_{t, x}^{i}},
$$

and similarly for the mimicker. The optimal marginal capital income tax rates in period $t+1$ are obtained by combining the government's first order conditions for $c_{t}^{i}$ and $x_{t+1}^{i}$, for $i=1,2$, with the private first-order condition for saving in period $t$ :

$$
\begin{aligned}
& \Phi_{t+1}^{\prime}\left(s_{t}^{1} r_{t+1}\right)=\frac{\lambda_{t} \hat{u}_{t, x}^{2}}{\gamma_{t+1} n_{t}^{1} r_{t+1}}\left[M R S_{c, x}^{1, t}-M \hat{R} S_{c, x}^{2, t}\right]+\frac{1}{\gamma_{t+1} r_{t+1}}\left[\frac{\partial \mathcal{L}}{\partial \bar{c}_{t}} \frac{1}{N_{t}}-M R S_{c, x}^{1, t} \frac{\partial \mathcal{L}}{\partial \bar{c}_{t+1}} \frac{1}{N_{t+1}}\right], \\
& \Phi_{t+1}^{\prime}\left(s_{t}^{2} r_{t+1}\right)=\frac{1}{\gamma_{t+1} r_{t+1}}\left[\frac{\partial \mathcal{L}}{\partial \bar{c}_{t}} \frac{1}{N_{t}}-M R S_{c, x}^{2, t} \frac{\partial \mathcal{L}}{\partial \bar{c}_{t+1}} \frac{1}{N_{t+1}}\right] .
\end{aligned}
$$

Let us start by discussing the marginal capital income tax rate of the low-ability type. The first term on the right-hand side of equation (20) is due to the self-selection constraint. It means that if the relative valuation of current consumption by the low-ability type exceeds (falls short of) the relative valuation by the mimicker, there is an incentive for the government to stimulate (discourage) the current consumption via a higher (lower) marginal capital income tax rate. As such, this incentive effect serves to relax the self-selection constraint by making mimicking less attractive (see also, e.g., Brett 1997 and Pirttilä and Tuomala 2001).

The second term, which takes the same general form as the expression for the marginal capital income tax rate facing the high-ability type, is novel and refers to the assumption that a private consumption good is, in part, a positional good. As the marginal capital income tax rates reflect a desired tradeoff for society between present and future consumption, each such term is decomposable into two parts. The intuition is, of course, that each individual generates positional externalities both when young and when old. By combining Lemma 1 with equations (20) and (21), we can derive the following result:

Proposition 3. If the young and old low-ability type, respectively, is at least as positional as the corresponding mimicker in periods $t$ and $t+1$, or if the positionality differences are sufficiently small so that $\partial \mathcal{L} / \partial \bar{c}_{t}$ and $\partial \mathcal{L} / \partial \bar{c}_{t+1}$ are both negative, then the positionality 
effect in period t contributes to decrease the marginal capital income tax rates in period $t+1$, whereas the positionality effect in period $t+1$ contributes to increase the marginal capital income tax rates in the same period, ceteris paribus.

The intuition behind Proposition 3 is straightforward. The positionality effect in period $t$ means that an increase in the reference consumption in period $t$ gives rise to a welfare loss. This provides an incentive for the government to choose lower marginal capital income tax rates than it would otherwise have done, which in turn stimulates savings and discourages consumption in period $t$. By analogy, the positionality effect in period $t+1$ means that an increase in the reference consumption in period $t+1$ results in a welfare loss. As a consequence, there is an incentive for the government to reduce the average consumption in period $t+1$, which means that the government chooses higher marginal capital income tax rates than it would otherwise have done. The relative sizes of these two effects determine whether the appearance of positional preferences constitutes an incentive to tax or subsidize the capital income at the margin, ceteris paribus.

Let us use the short notation $\delta_{t}^{i}$ for the optimal marginal capital income tax rate that would follow in the absence of any positionality effects, i.e.,

$$
\delta_{t}^{1}=\frac{\lambda_{t} \hat{u}_{t, x}^{2}}{\gamma_{t+1} n_{t}^{1} r_{t+1}}\left[M R S_{c, x}^{1, t}-M \hat{R} S_{c, x}^{2, t}\right] \text { and } \delta_{t}^{2}=0 .
$$

Then, using the decomposition of the positionality effect given by equation (16), we obtain

$$
\Phi_{t+1}^{\prime}\left(s_{t}^{i} r_{t+1}\right)=\delta_{t}^{i} \frac{1-\bar{\alpha}_{t+1}}{1-\Gamma_{t+1}}+\frac{1-\bar{\alpha}_{t+1}}{1-\Gamma_{t+1}}\left(1+\frac{1}{r_{t+1}}\right)\left[\frac{\bar{\alpha}_{t+1}-\Gamma_{t+1}}{1-\bar{\alpha}_{t+1}}-\frac{\bar{\alpha}_{t}-\Gamma_{t}}{1-\bar{\alpha}_{t}}\right] .
$$

In equation (22), the first term on the right-hand side means that positional concerns may modify the traditional self-selection component in the tax formula for the low-ability type, which will be explained more thoroughly below. The sign of the second term is clearly positive (negative) if and only if the expression in square-brackets is positive (negative), which is the case when the average net degree of positionality - i.e., the average degree of positionality adjusted for the self-selection effect - increases (decreases) over time. ${ }^{14}$ The

\footnotetext{
${ }^{14}$ Strictly speaking, this result also presupposes that $1-\Gamma_{t+1}>0$.
} 
intuition is that future increases in the degree of positionality constitute incentives for the government to reduce consumption in the future, which it does by implementing a higher marginal capital income tax rate than it would otherwise have done.

In the special case where the average degree of positionality and the difference in the degree of positionality between the mimicker and the low-ability type are constant over time, equation (22) can be simplified. This situation may arise either if the economy approaches a steady state ${ }^{15}$ or from functional form restrictions on the utility function beyond those presented in Section 2 (see below). Consider the following result, which is an implication of equation (22):

Proposition 4. If the average degree of positionality as well as the positionality differences between the mimicker and the low-ability type remain constant over time, so $\bar{\alpha}_{t+1}=\bar{\alpha}_{t}=\bar{\alpha}$ and $\Gamma_{t+1}=\Gamma_{t}=\Gamma$, then the marginal capital income tax rates reduce to

$$
\begin{aligned}
& \Phi_{t+1}^{\prime}\left(s_{t}^{1} r_{t+1}\right)=\frac{\lambda_{t} \hat{u}_{t, x}^{2}}{\gamma_{t+1} n_{t}^{1} r_{t+1}}\left[M R S_{c, x}^{1, t}-M \hat{R} S_{c, x}^{2, t}\right] \frac{1-\bar{\alpha}}{1-\Gamma}, \\
& \Phi_{t+1}^{\prime}\left(s_{t}^{2} r_{t+1}\right)=0 .
\end{aligned}
$$

Note that there is no direct effect of positionality in these tax formulas. Therefore, in this special case, the appearance of positionality does not change the way we measure the marginal capital income tax rate of the high-ability type (compared to an economy without positional goods). The intuition is that under the conditions in the proposition, the current and future aspects of positionality cancel each other out to a large extent, suggesting that the incentives underlying capital formation are similar to those that would apply in economies without positional goods. However, this does not mean that the effect of positionality that still remains for the low-ability type is unimportant.

As long as leisure is not weakly separable from private consumption, the low-ability type and the mimicker will differ with respect to the relative value attached to current consumption.

\footnotetext{
${ }^{15}$ This requires that the preferences and technology do not change over time, and that the economy approaches a stationary equilibrium in which $l_{t}^{i}, c_{t}^{i}, x_{t}^{i}$ (for $\left.i=1,2\right)$, and $K_{t}$ all remain constant over time.
} 
The contribution of this difference to the marginal capital income tax rate of the low-ability type is still affected by concern for positionality. To interpret the "positionality-weight" $[1-\bar{\alpha}] /[1-\Gamma]$, consider first the situation where $M R S_{c, x}^{1, t}>M \hat{R} S_{c, x}^{2, t}$, meaning that the first term on the right-hand side of equation (23) contributes to increase the marginal capital income tax rate of the low-ability type. As such, this term works to increase the current (first period) consumption of the low-ability type and, as a consequence, also the reference consumption in period $t$. The expression $1-\bar{\alpha}$ serves to modify this effect, as increased reference consumption gives rise to positional externalities. In other words, if we (for the moment) were to abstract from differences in the degree of positionality between the mimicker and the low-ability type, implying that $\Gamma=0$, then the positionality-weight would work to decrease the marginal capital income tax rate. This effect is counteracted (further strengthened) by $\Gamma>0(<0)$, as increased reference consumption in this case relaxes (tightens) the selfselection constraint in period $t$. The interpretation is analogous if $M R S_{c, x}^{1, t}<M \hat{R} S_{c, x}^{2, t}$; yet with the modification that the positionality-weight then serves to adjust the effect that a capital subsidy has in terms of future consumption.

Let us also discuss the marginal capital income tax rates in the light of the empirical evidence regarding relative consumption concerns described above. For simplicity, let us first focus on the case illustrated in Proposition 4, in which positional concerns only affect the marginal capital income tax rate of the low-ability type. As with the marginal labor income tax rates, we concentrate the discussion on the contribution of the average degree of positionality by assuming that $\Gamma=0$; the reason is again the lack of clear empirical evidence regarding differences in the degree of positionality across agent types. In this (highly simplified) case, equation (23) suggests that the absolute value of the marginal capital income tax rate may be substantially smaller than would be predicted in the absence of positional concerns. In fact, with the expression proportional to $1-\bar{\alpha}$ held constant, ${ }^{16}$ the positionality effect with $\bar{\alpha}$ being between 0.2 and 0.8 contributes to scale down the absolute value of the marginal capital income tax rate by a factor between 1.2 and 5. Therefore, if $M R S_{c, x}^{1, t}>M \hat{R} S_{c, x}^{2, t}$, the relative consumption concerns imply an incentive for the government to adjust the capital

\footnotetext{
${ }^{16}$ In reality, positional concerns of course give rise to indirect effects on the other terms as well. Therefore, this discussion only refers to the direct influence of the positionality effect.
} 
income tax to discourage the current relative to the future consumption; a policy response reminiscent to the consumption tax discussed by Frank (1999, 2007, 2008). However, assume now instead that the degree of positionality increases with income, which is in line with some empirical evidence (Clark et al. 2008) and as argued already by Keynes (1930). A growing economy would then imply that the degree of positionality would also increase over time, which from equation (22) ceteris paribus works in the direction of a positive marginal capital income tax rate for both ability-types.

The following result is a direct consequence of Proposition 4:

Corollary 1. Suppose that the average degree of positionality as well as the positionality differences between the mimicker and the low-ability type remain constant over time. Then, if leisure is weakly separable from private consumption in the sense that $U_{t}^{i}=q_{t}^{i}\left(f_{t}\left(c_{t}^{i}, x_{t+1}^{i}, \Delta_{t}^{i, c}, \Delta_{t+1}^{i, x}\right), z_{t}^{i}\right)$ describes the utility function, then both optimal marginal capital income tax rates are zero.

Note that while the function $q_{t}^{i}(\cdot)$ may vary across ability-types, the function $f_{t}(\cdot)$ must be the same for both ability-types. Although the above result is based on assumptions that may not seem entirely realistic, it is nevertheless interesting from the perspective of comparison with earlier literature. Corollary 1 implies that the important result derived by Ordover and Phelps (1979), for when capital income taxation is not needed, carries over to our more general case that includes relative consumption concerns.

To give a functional form example, note finally that the conditions underlying Corollary 1 would be fulfilled with a constant population growth rate together with a utility function given as follows (for $i=1,2$ ):

$$
\begin{aligned}
U_{t}^{i} & =\frac{k^{i}\left[z_{t}^{i}\left[[1-a] c_{t}^{i}+a\left[c_{t}^{i}-\bar{c}_{t}\right]\right]\left[[1-b] x_{t+1}^{i}+b\left[x_{t+1}^{i}-\bar{c}_{t+1}\right]\right]\right]^{1-e^{i}}}{1-e^{i}}, \\
& =\frac{k^{i}\left[z_{t}^{i}\left[c_{t}^{i}-a \bar{c}_{t}\right]\left[x_{t+1}^{i}-b \bar{c}_{t+1}\right]\right]^{1-e^{i}}}{1-e^{i}}
\end{aligned}
$$

where $k^{i}>0$ and $e^{i} \in(0,1)$ are ability-type specific parameters, and $a$ and $b$ are constants such that $0<a, b<1$. This example does not presuppose that the economy has reached a 
steady state. Instead, it follows immediately from the formulation in the first row that the degree of positionality is equal to $a$ when young and $b$ when old for each ability-type (and for the mimicker). ${ }^{17}$ It is also straightforward to show that $M R S_{c, x}^{i, t}-$ when calculated on the basis of this utility function - does not directly depend on $z_{t}^{i}$ so that $M R S_{c, x}^{1, t}=M \hat{R} S_{c, x}^{2, t}$ and, therefore, $\Phi_{t+1}^{\prime}\left(s_{t}^{1} r_{t+1}\right)=0$.

\section{ALTERNATIVE REFERENCE POINTS: WITHIN GENERATION AND UPWARD SOCIAL COMPARISONS}

So far, we have assumed that the average consumption in the economy as a whole constitutes the appropriate measure of reference consumption, which follows earlier comparable literature. However, what constitutes the most appropriate measure of reference consumption can be discussed, and one may argue that people compare themselves more with some people than with others. In particular, it is possible that people primarily compare their own consumption with the consumption by people in their own generation. Alternatively, one may argue that people primarily compare themselves with high-income earners, as suggested by, e.g., Duesenberry (1949). In subsection 6.1, we consider the case where people make withingeneration comparisons, whereas subsection 6.2 analyzes the case where people solely compare themselves with the high-ability type. In all other respects, we again make the same assumptions, e.g., with respect to the production sector and available policy instruments, as in the previous sections. ${ }^{18}$

\subsection{Within-generation consumption comparisons}

When people solely make within-generation consumption comparisons, the utility function of ability-type $i$ born in the beginning of period $t$ can be written as

17 Alternatively, the conditions in the corollary would be fulfilled irrespective of the population growth rate if the utility function takes the form

$$
U_{t}^{i}=\frac{k^{i}\left[z_{t}^{i}\left[c_{t}^{i}-a \bar{c}_{t}\right]\left[x_{t+1}^{i}-a \bar{c}_{t+1}\right]\right]^{1-e^{i}}}{1-e^{i}},
$$

so that the degree of positionality is equal to $a$ for all.

${ }^{18}$ One may also argue that people are likely to make consumption comparisons over time, e.g., with earlier generations; see the background working paper by Aronsson and Johansson-Stenman (2008b). 


$$
\begin{aligned}
U_{t}^{i} & =v_{t}^{i}\left(c_{t}^{i}, z_{t}^{i}, x_{t+1}^{i}, c_{t}^{i}-\bar{c}_{t, t}, x_{t+1}^{i}-\bar{x}_{t+1, t}\right)=v_{t}^{i}\left(c_{t}^{i}, z_{t}^{i}, x_{t+1}^{i}, \Delta_{t}^{i, c c}, \Delta_{t+1}^{i, x x}\right) \\
& =u_{t}^{i}\left(c_{t}^{i}, z_{t}^{i}, x_{t+1}^{i}, \bar{c}_{t, t}, \bar{x}_{t+1, t}\right)
\end{aligned}
$$

As before, the utility function $v_{t}^{i}(\cdot)$ is increasing in each argument, implying that $u_{t}^{i}(\cdot)$ is decreasing in each average consumption level; $\bar{c}_{t, t}=\left[n_{t}^{1} c_{t}^{1}+n_{t}^{2} c_{t}^{2}\right] /\left[n_{t}^{1}+n_{t}^{2}\right]$ represents the average consumption in period $t$ measured for the generation born in period $t$, whereas the average consumption by the same generation when old in period $t+1$ is given by $\bar{x}_{t+1, t}=\left[n_{t}^{1} x_{t+1}^{1}+n_{t}^{2} x_{t+1}^{2}\right] /\left[n_{t}^{1}+n_{t}^{2}\right]$. Based on equation (25), we can calculate withingeneration measures of positionality as follows:

$$
\begin{aligned}
& \alpha_{t}^{i, c c}=\frac{v_{t, \Delta_{t}^{c c}}^{i}}{v_{t, \Delta_{t}^{i c c}}^{i}+v_{t, c}^{i}}, \\
& \alpha_{t+1}^{i, x x}=\frac{v_{t, \Delta_{t+1}^{x x}}^{i}}{v_{t, \Delta_{t+1}^{i x}}^{i}+v_{t, x}^{i}},
\end{aligned}
$$

where $\alpha_{t}^{i, c c}$ can be interpreted as the fraction of the overall utility increase from the last dollar spent by a young individual of ability-type $i$ in period $t$ that is due to the increased relative consumption compared to other young people in period $t$, whereas $\alpha_{t+1}^{i, x x}$ reflects the corresponding fraction compared to other old people when old in period $t+1$.

We will now have two positionality effects. The welfare effect of an increase in the average consumption among the young in period $t, \bar{c}_{t, t}$ can be written as

$$
\frac{\partial \mathcal{L}}{\partial \bar{c}_{t, t}}=-\frac{\gamma_{t} n_{t} \bar{\alpha}_{t}^{c c}}{1-\bar{\alpha}_{t}^{c c}}+\frac{\lambda_{t} \hat{u}_{t, c}^{2}}{1-\bar{\alpha}_{t}^{c c}}\left[\hat{\alpha}_{t}^{2, c c}-\alpha_{t}^{1, c c}\right]
$$

whereas the corresponding effect of an increase in the average consumption among the old in period $t+1, \bar{x}_{t+1, t}$ can be written as 


$$
\frac{\partial \mathcal{L}}{\partial \bar{x}_{t+1, t}}=-\frac{\gamma_{t+1} n_{t} \bar{\alpha}_{t+1}^{x x}}{1-\bar{\alpha}_{t+1}^{x x}}+\frac{\lambda_{t} \hat{u}_{t, x}^{2}}{1-\bar{\alpha}_{t+1}^{x x}}\left[\hat{\alpha}_{t+1}^{2, x x}-\alpha_{t+1}^{1, x x}\right]
$$

In equations (27a) and (27b), $\bar{\alpha}_{t}^{c c}$ and $\bar{\alpha}_{t+1}^{x x}$ are within-generation measures of the average degree of positionality. Clearly, and by analogy to equation (16), each positionality effect is negative unless the mimicker is sufficiently more positional than the low-ability type, i.e., unless the self-selection effect has the opposite sign of, and dominates, the direct effect; cf. Lemma 1.

By using the short notation

$$
\Gamma_{t}^{c}=\frac{\lambda_{t} \hat{u}_{t, c}^{2}}{\gamma_{t} n_{t}}\left[\hat{\alpha}_{t}^{2, c c}-\alpha_{t}^{1, c c}\right],
$$

where $n_{t}=n_{t}^{1}+n_{t}^{2}$, we can then write the optimal marginal labor income tax rate for abilitytype $i$ (for $i=1,2$ ) in the same general form as before:

$$
T_{t}^{\prime}\left(w_{t}^{i} l_{t}^{i}\right)=\sigma_{t}^{i}+\left[1-\sigma_{t}^{i}\right] \bar{\alpha}_{t}^{c c}-\left[1-\sigma_{t}^{i}\right]\left[1-\bar{\alpha}_{t}^{c c}\right] \frac{\Gamma_{t}^{c}}{1-\Gamma_{t}^{c}} .
$$

The only differences between equation (28) and the corresponding tax formula in subsection 4.1, i.e., equation (19), are (i) that the average degree of positionality is here replaced by the corresponding within-generation measure, and (ii) the difference in the degree of positionality between the mimicker and the low-ability type is here based on the within-generation measure. In other words, it is only the positionality of the young generation, i.e., of those working, that matters for the marginal labor income tax rates. The reason is, of course, that each young individual only imposes positional consumption externalities on other individuals of the same generation. The interpretation of equation (28) is otherwise analogous to that of equation (19).

The optimal marginal capital income tax rates can be written as

$$
\Phi_{t+1}^{\prime}\left(s_{t}^{1} r_{t+1}\right)=\frac{\lambda_{t} \hat{u}_{t, x}^{2}}{\gamma_{t+1} n_{t}^{1} r_{t+1}}\left[M R S_{c, x}^{1, t}-M \hat{R} S_{c, x}^{2, t}\right]+\frac{1}{\gamma_{t+1} r_{t+1}}\left[\frac{\partial \mathcal{L}}{\partial \bar{c}_{t, t}} \frac{1}{n_{t}}-M R S_{c, x}^{1, t} \frac{\partial \mathcal{L}}{\partial \bar{x}_{t+1, t}} \frac{1}{n_{t}}\right],
$$




$$
\Phi_{t+1}^{\prime}\left(s_{t}^{2} r_{t+1}\right)=\frac{1}{\gamma_{t+1} r_{t+1}}\left[\frac{\partial \mathcal{L}}{\partial \bar{c}_{t, t}} \frac{1}{n_{t}}-M R S_{c, x}^{2, t} \frac{\partial \mathcal{L}}{\partial \bar{x}_{t+1, t}} \frac{1}{n_{t}}\right]
$$

The main interpretations are again similar to the previously analyzed case, implying that Proposition 3 will hold here to. By using the within-generation positionality effects together with the short notation

$$
\Gamma_{t+1}^{x}=\frac{\lambda_{t} \hat{u}_{t, x}^{2}}{\gamma_{t+1} n_{t}}\left[\hat{\alpha}_{t+1}^{2, x x}-\alpha_{t+1}^{1, x x}\right]
$$

we can derive the following result (for $i=1,2$ ):

$$
\Phi_{t+1}^{\prime}\left(s_{t}^{i} r_{t+1}\right)=\delta_{t}^{i} \frac{1-\bar{\alpha}_{t+1}^{x x}}{1-\Gamma_{t+1}^{x}}+\frac{1-\bar{\alpha}_{t+1}^{x x}}{1-\Gamma_{t+1}^{x}}\left[1+\frac{1}{r_{t+1}}\right]\left[\frac{\bar{\alpha}_{t+1}^{x x}-\Gamma_{t+1}^{x}}{1-\bar{\alpha}_{t+1}^{x x}}-\frac{\bar{\alpha}_{t}^{c c}-\Gamma_{t}^{c}}{1-\bar{\alpha}_{t}^{c c}}\right] .
$$

Equation (31) is analogous to equation (22) with the exception that the measures of positionality in equation (31) are within-generation measures. The second term on the righthand side of equation (31) is positive (negative), if and only if the average net degree of positionality, i.e., the average degree of positionality adjusted for the self-selection effect, is larger (smaller) when old than when young. Intuitively, a high degree of positionality means a larger social waste from consumption. Therefore, if the old are less positional than the young, which seems reasonable from an evolutionary perspective and for which there is actually some empirical evidence (e.g., Pingle and Mitchell 2002; Johansson-Stenman and Martinsson 2006), it is for this reason optimal to have a negative marginal capital income tax rate, i.e., subsidize savings. Note also that a negative marginal capital income tax rate has similarities with a progressive consumption tax, as discussed by Frank (1999, 2007, 2008).

Finally, and by analogy with the results derived earlier, it follows that the marginal capital income tax rate is zero for both ability-types if the average net degree of positionality is equally large when young and when old, and if leisure is weakly separable from the other goods in the sense that the utility function can be written as $U_{t}^{i}=q_{t}^{i}\left(f_{t}\left(c_{t}^{i}, x_{t+1}^{i}, \Delta_{t}^{i, c c}, \Delta_{t+1}^{i, x x}\right), z_{t}^{i}\right)$.

\subsection{Upward social comparisons}

There are several possible ways to model upward comparisons; for instance, that only the low-ability type makes such comparisons or that all individuals compare themselves with the 
average consumption among high-ability agents. ${ }^{19}$ We will choose the latter approach primarily because it is more general than the former (the latter encompasses the former as a special case). When each individual solely compares his/her own consumption with the average consumption of the high-ability type, the utility function of ability-type $i$ born in period $t$ can be written as

$$
U_{t}^{i}=v_{t}^{i}\left(c_{t}^{i}, z_{t}^{i}, x_{t+1}^{i}, c_{t}^{i}-\bar{c}_{t}^{2}, x_{t+1}^{i}-\bar{c}_{t+1}^{2}\right)=v_{t}^{i}\left(c_{t}^{i}, z_{t}^{i}, x_{t+1}^{i}, \Delta_{t}^{i 2, c}, \Delta_{t+1}^{i 2, x}\right)=u_{t}^{i}\left(c_{t}^{i}, z_{t}^{i}, x_{t+1}^{i}, \bar{c}_{t}^{2}, \bar{c}_{t+1}^{2}\right),
$$

where $\bar{c}_{t}^{2}=\left[n_{t}^{2} c_{t}^{2}+n_{t-1}^{2} x_{t}^{2}\right] /\left[n_{t}^{2}+n_{t-1}^{2}\right]$ represents the average consumption among highability individuals at time $t$. We can then define the degree of upward consumption positionality when young and when old, respectively, as

$$
\begin{aligned}
& \alpha_{t}^{i 2, c}=\frac{v_{t, \Delta_{t}^{2 c}}^{i}}{v_{t, \Delta_{t}^{2 c}}^{i}+v_{t, c}^{i}}, \\
& \alpha_{t+1}^{i 2, x}=\frac{v_{t, \Delta_{t+1}^{2 x}}^{i}}{v_{t, \Delta_{t+1}^{2 x}}^{i}+v_{t, x}^{i}},
\end{aligned}
$$

where $\alpha_{t}^{i 2, c}$ reflects the fraction of the overall utility increase from the last dollar spent by an individual of ability-type $i$ in period $t$ that is due to the increased relative consumption compared to high-ability individuals; $\alpha_{t+1}^{i 2, x}$ reflects the corresponding fraction when old instead of when young. We can then define the average degree of upward consumption positionality as

$$
\bar{\alpha}_{t}^{2}=\sum_{i} \alpha_{t}^{i 2, x} \frac{n_{t-1}^{i}}{N_{t}}+\sum_{i} \alpha_{t}^{i 2, c} \frac{n_{t}^{i}}{N_{t}},
$$

where $N_{t}=n_{t}^{1}+n_{t}^{2}+n_{t-1}^{1}+n_{t-1}^{2}$ as before.

Note that all positional externalities are, in this case, generated by the behavior of the highability type. As a consequence, the marginal labor income and capital income tax rates implemented for the low-ability type will correspond to the standard model (in which goods

\footnotetext{
${ }^{19}$ Micheletto (2008) also analyzes upward comparisons in an economy with positional preferences. Yet, his framework differs from ours in several fundamental ways; he uses a static model without capital income taxation, and only allows the low-ability type to be positional.
} 
are completely non-positional). Thus, using the notation introduced above, we have $T_{t}^{\prime}\left(w^{1} l^{1}\right)=\sigma_{t}^{1}$ and $\Phi_{t+1}^{\prime}\left(s_{t}^{1} r_{t+1}\right)=\delta_{t}^{1}$, respectively. Then, if we use the short notation

$$
\begin{aligned}
& \Gamma_{t}^{2}=\frac{\lambda_{t-1} \hat{u}_{t-t, x}^{2}}{\gamma_{t} N_{t}}\left[\hat{\alpha}_{t}^{22, x}-\alpha_{t}^{12, x}\right]+\frac{\lambda_{t} \hat{u}_{t, c}^{2}}{\gamma_{t} N_{t}}\left[\hat{\alpha}_{t}^{22, c}-\alpha_{t}^{12, c}\right] \\
& \omega_{t}=\frac{\left(1-\bar{\alpha}_{t}^{22}\right)+\left(1 / \kappa_{t}^{2}\right)\left(\bar{\alpha}_{t}^{2}-\Gamma_{t}^{2}\right)}{\left(1-\bar{\alpha}_{t}^{22}\right)},
\end{aligned}
$$

where $\bar{\alpha}_{t}^{22}=\left(n_{t}^{2} \alpha_{t}^{22, c}+n_{t-t}^{2} \alpha_{t}^{22, x}\right) / N_{t}, N_{t}^{2}=n_{t}^{2}+n_{t-1}^{2}$, and $\kappa_{t}^{2}=N_{t}^{2} / N_{t}$ is the share of highability agents, the corresponding tax formulas for the high-ability type can be written as

$$
\begin{gathered}
T_{t}^{\prime}\left(w_{t}^{2} l_{t}^{2}\right)=\frac{1}{\omega_{t} \kappa_{t}^{2}}\left[\frac{\bar{\alpha}_{t}^{2}-\Gamma_{t}^{2}}{1-\bar{\alpha}_{t}^{22}}\right], \\
\Phi_{t+1}^{\prime}\left(s_{t}^{2} r_{t+1}\right)=\frac{1}{\omega_{t+1}}\left[1+\frac{1}{r_{t+1}}\right]\left[\frac{\bar{\alpha}_{t+1}^{2}-\Gamma_{t+1}^{2}}{1-\bar{\alpha}_{t+1}^{22}} \frac{1}{\kappa_{t+1}^{2}}-\frac{\bar{\alpha}_{t}^{2}-\Gamma_{t}^{2}}{1-\bar{\alpha}_{t}^{22}} \frac{1}{\kappa_{t}^{2}}\right] .
\end{gathered}
$$

Equations (34) and (35) closely resemble their counterparts in Section 4, and each formula permits an analogous interpretation in terms of the net degree of consumption positionality. However, there is one important difference: in this case, the optimal policy response to positional concerns is to modify the marginal income tax rates for the high-ability type only, whereas the corresponding marginal income tax rates for the low-ability type remain as in the standard model. The reason is, of course, that the low-ability type does not generate any positional externalities in this case.

The "positional arms race" per se may seem to be particularly detrimental for the low-ability type in the case of upward social comparisons, since the low-ability type is directly affected by the high-ability type's consumption, whereas the high-ability type is not directly affected by the low-ability type's consumption. Yet, the results here suggest that the potential redistributional effect (favoring the low-ability type) of an optimal income tax system that takes into account such positional externalities might be especially large in the case of upward comparisons, since the externality-correcting tax component will be paid only by the high-ability type. ${ }^{20}$

\footnotetext{
${ }^{20}$ Frank $(2007,2008)$ argues that the U.S. middle class has suffered severely from the positional arms race. In order to analyze more than two classes, we clearly need a richer model. However, it appears to us that several of
} 


\section{CONCLUSION}

As far as we know, the present paper is the first to consider optimal nonlinear income taxation in a second-best economy with asymmetric information, where people care about relative consumption, based on a dynamic (OLG) model. The model used is an extension of the standard optimal nonlinear income tax model with two ability-types. Our paper also recognizes the idea that each individual may compare himself/herself more with some people than with others. Therefore, in addition to measures of reference consumption based on the average consumption in the economy as a whole, we also considered within-generation and upward comparisons.

We began by analyzing the case where the reference consumption is equal to the average consumption. Our results show that the more positional people are on average, ceteris paribus, the higher the marginal labor income tax rates. The intuition is that a higher marginal labor income tax rate reduces hours of work and, therefore, the resources available for private consumption. As a consequence, it also reduces the reference consumption to which people compare their own consumption. The effect of positional preferences on the marginal labor income tax rates also depends on whether the (mimicked) low-ability type is more or less positional than the mimicker, as this will determine whether an increase or a decrease in the reference consumption works to relax the self-selection constraint. Therefore, as the mimicker uses more leisure than the low-ability type (while mimicking the low-ability type in income-consumption space), our results suggest that the relationship between, on the one hand, the degree of positionality and, on the other, the use of leisure would constitute valuable information from the perspective of tax policy. By using the (scarce) available empirical evidence, our model implies that the optimal marginal labor income tax rates are likely to be much higher than suggested by models without relative consumption comparisons.

The effects of positional preferences on the marginal capital income tax rates are ambiguous in general. This also accords well with intuition, as the marginal capital income tax rates

the implications to the middle class discussed by Frank can be interpreted in terms of the low-ability type in our model. 
reflect a tradeoff between present and future consumption. The more the average net degree of positionality (i.e., the average degree of positionality adjusted for the self-selection effect) increases (decreases) over time, ceteris paribus, the higher (lower) will be the marginal capital income tax rate. In the special case where the degree of positionality is constant over time and across agent-types, plausible empirical estimates suggest that the marginal capital income tax rate of the low-ability type may be substantially smaller in absolute value than in the conventional optimal income tax model. In addition, if the degree of positionality is constant over time and across agent-types, we are able to generalize the well-known result of Ordover and Phelps (1979) to a model with positional preferences; in other words, if leisure is weakly separable from the other goods in the utility function, then the marginal capital income tax rates should be zero.

The alternative measures of reference consumption, i.e., those based on within-generation or upward comparisons, allow us to explore some implications of the possibility that individuals compare themselves more with some people than with others. Within-generation comparisons give tax formulas in the same format as those based on average consumption comparisons. However, an important difference is that for within-generation comparisons, individuals only impose positional externalities on other people of the same generation; as a consequence, the policy rules for marginal income taxation ought to be interpreted in light of this more narrow interaction. For example, here it becomes important for marginal capital income taxation whether people become more or less positional as they grow old. If they become less positional, then ceteris paribus this is a case for negative marginal capital income taxes, and vice versa.

In the case of upward comparisons, the marginal labor income and capital income tax rates of the low-ability type remain as in the standard model, whereas the corresponding marginal income tax rates for the high-ability type are modified since each high-ability individual imposes positional externalities on other people. The intuition is that the behavior of the lowability type does not contribute to the externalities generated in the positional arms race. As a consequence, internalization of positional externalities through income taxes has potentially very large redistributional effects in this case.

Finally, although the present paper in several respects generalizes the literature on optimal taxation when relative consumption matters, there are still many important aspects left to 
explore. Examples include a multi-country setting, public good provision in a dynamic economy, and the case where also relative leisure matters. We hope to address these issues in future research.

\section{Appendix}

\section{Results of the base case; Sections 3 and 4}

First-order conditions

The first-order conditions for $l_{t}^{1}, c_{t}^{1}, x_{t+1}^{1}, l_{t}^{2}, c_{t}^{2}, x_{t+1}^{2}$, and $K_{t+1}$ are given by

$$
\begin{aligned}
& -\frac{\partial W}{\partial\left(n_{t}^{1} U_{t}^{1}\right)} n_{t}^{1} u_{t, z}^{1}+\phi \lambda_{t} \hat{u}_{t, z}^{2}+\gamma_{t} n_{t}^{1} w_{t}^{1}=0, \\
& \frac{\partial W}{\partial\left(n_{t}^{1} U_{t}^{1}\right)} n_{t}^{1} u_{t, c}^{1}-\lambda_{t} \hat{u}_{t, c}^{2}-\gamma_{t} n_{t}^{1}+\frac{n_{t}^{1}}{N_{t}} \frac{\partial \mathcal{L}}{\partial \bar{c}_{t}}=0,
\end{aligned}
$$

$$
\frac{\partial W}{\partial\left(n_{t}^{1} U_{t}^{1}\right)} n_{t}^{1} u_{t, x}^{1}-\lambda_{t} \hat{u}_{t, x}^{2}-\gamma_{t+1} n_{t}^{1}+\frac{n_{t}^{1}}{N_{t+1}} \frac{\partial \mathcal{L}}{\partial \bar{c}_{t+1}}=0,
$$$$
-\left[\frac{\partial W}{\partial\left(n_{t}^{2} U_{t}^{2}\right)} n_{t}^{2}+\lambda_{t}\right] u_{t, z}^{2}+\gamma_{t} n_{t}^{2} w_{t}^{2}=0,
$$$$
\left[\frac{\partial W}{\partial\left(n_{t}^{2} U_{t}^{2}\right)} n_{t}^{2}+\lambda_{t}\right] u_{t, c}^{2}-\gamma_{t} n_{t}^{2}+\frac{n_{t}^{2}}{N_{t}} \frac{\partial \mathcal{L}}{\partial \bar{c}_{t}}=0,
$$

$$
\left[\frac{\partial W}{\partial\left(n_{t}^{2} U_{t}^{2}\right)} n_{t}^{2}+\lambda_{t}\right] u_{t, x}^{2}-\gamma_{t+1} n_{t}^{2}+\frac{n_{t}^{2}}{N_{t+1}} \frac{\partial \mathcal{L}}{\partial \bar{c}_{t+1}}=0,
$$

where we have used $w_{t}^{i}=F_{L^{i}}\left(L_{t}^{1}, L_{t}^{2}, K_{t} ; t\right)$ for $i=1,2$, and $r_{t}=F_{K}\left(L_{t}^{1}, L_{t}^{2}, K_{t} ; t\right)$ from the firstorder conditions of the firm.

\section{Proof of Lemma 1}

From equation (1) we have that $u_{t, c}^{i}=v_{t, c}^{i}+v_{t, \Delta_{t}^{c}}^{i}, \quad u_{t, \bar{c}_{t}}^{i}=-v_{t, \Delta_{t}^{c}}^{i}, \quad u_{t, x}^{i}=v_{t, x}^{i}+v_{t, \Delta_{t+1}^{x}}^{i}$, and $u_{t, \bar{c}_{t+1}}^{i}=-v_{t, \Delta_{t+1}^{x}}^{i}$, so

$$
\begin{aligned}
& u_{t, \bar{c}_{t}}^{i}=-\alpha_{t}^{i, c} u_{t, c}^{i}, \\
& u_{t, \bar{c}_{t+1}^{i}}^{i}=-\alpha_{t+1}^{i, x} u_{t, x}^{i} .
\end{aligned}
$$


Corresponding expressions hold for the mimicker. By combining equations (15), (A8), and (A9), and the corresponding expressions for the mimicker, we obtain

$$
\begin{aligned}
\frac{\partial \mathcal{L}}{\partial \bar{c}_{t}} & =-\sum_{i=1}^{2} \frac{\partial W}{\partial\left(n_{t-1}^{i} u_{t-1}^{i}\right)} n_{t-1}^{i} \alpha_{t}^{i, x} u_{t-1, x}^{i}-\sum_{i=1}^{2} \frac{\partial W}{\partial\left(n_{t}^{i} u_{t}^{i}\right)} n_{t}^{i} \alpha_{t}^{i, c} u_{t, c}^{i} \\
& -\lambda_{t-1}\left[\alpha_{t}^{2, x} u_{t-1, x}^{2}-\hat{\alpha}_{t}^{2, x} \hat{u}_{t-1, x}^{2}\right]-\lambda_{t}\left[\alpha_{t}^{2, c} u_{t, c}^{2}-\hat{\alpha}_{t}^{2, c} \hat{u}_{t, c}^{2}\right]
\end{aligned} .
$$

Note that equations (A2), (A3), (A5), and (A6) imply

$$
\begin{aligned}
& \frac{\partial W}{\partial\left(n_{t}^{1} U_{t}^{1}\right)} n_{t}^{1} u_{t, c}^{1}=\lambda_{t} \hat{u}_{t, c}^{2}+\gamma_{t} n_{t}^{1}-\frac{n_{t}^{1}}{N_{t}} \frac{\partial \mathcal{L}}{\partial \bar{c}_{t}}, \\
& \frac{\partial W}{\partial\left(n_{t}^{2} U_{t}^{2}\right)} n_{t}^{2} u_{t, c}^{2}=-\lambda_{t} u_{t, c}^{2}+\gamma_{t} n_{t}^{2}-\frac{n_{t}^{2}}{N_{t}} \frac{\partial \mathcal{L}}{\partial \bar{c}_{t}}, \\
& \frac{\partial W}{\partial\left(n_{t-1}^{1} U_{t-1}^{1}\right)} n_{t-1}^{1} u_{t-1, x}^{1}=\lambda_{t-1} \hat{u}_{t-1, x}^{2}+\gamma_{t} n_{t-1}^{1}-\frac{n_{t-1}^{1}}{N_{t}} \frac{\partial \mathcal{L}}{\partial \bar{c}_{t}}, \\
& \frac{\partial W}{\partial\left(n_{t-1}^{2} U_{t-1}^{2}\right)} n_{t-1}^{2} u_{t-1, x}^{2}=-\lambda_{t-1} u_{t-1, x}^{2}+\gamma_{t} n_{t-1}^{2}-\frac{n_{t-1}^{2}}{N_{t}} \frac{\partial \mathcal{L}}{\partial \bar{c}_{t}} .
\end{aligned}
$$

Substituting equations (A11)-(A14) and the definition of $\Gamma_{t}$ into equation (A10) gives equation (16).

\section{The Marginal Labor Income Tax Rates}

Consider the tax formula for the low-ability type. By combining equations (A1) and (A2), we obtain

$$
\frac{u_{t, z}^{1}}{u_{t, c}^{1}}\left[\lambda_{t} \hat{u}_{t, c}^{2}+\gamma_{t} n_{t}^{1}-\frac{n_{t}^{1}}{N_{t}} \frac{\partial \mathcal{L}}{\partial \bar{c}_{t}}\right]=\lambda_{t} \phi \hat{u}_{t, z}^{2}+\gamma_{t} n_{t}^{1} w_{t}^{1} .
$$

By substituting $T_{t}^{\prime}\left(w_{t}^{1} l_{t}^{1}\right) w_{t}^{1}=w_{t}^{1}-u_{t, z}^{1} / u_{t, c}^{1}$ into equation (A15) and rearranging, we obtain equation (17). The marginal labor income tax rate of the high-ability type, equation (18), can be derived in a similar way.

To derive equation (19), we combine equations (16) and (17) to obtain

$$
\begin{aligned}
& T_{t}^{\prime}\left(w_{t}^{1} l_{t}^{1}\right)=\frac{\lambda_{t}^{*}}{w_{t}^{1} n_{t}^{1}}\left[M R S_{z, c}^{1, t}-\phi M \hat{R} S_{z, c}^{2, t}\right] \\
& -\frac{M R S_{z, c}^{1, t}}{\gamma_{t} w_{t}^{1} N_{t}} \frac{1}{1-\bar{\alpha}_{t}}\left[-\lambda_{t-1}\left[\alpha_{t}^{1, x}-\hat{\alpha}_{t}^{2, x}\right] \hat{u}_{t-1, x}^{2}-\lambda_{t}\left[\alpha_{t}^{1, c}-\hat{\alpha}_{t}^{2 c}\right] \hat{u}_{t, c}^{2}-\gamma_{t} N_{t} \bar{\alpha}_{t}\right]
\end{aligned}
$$


Then, by using $M R S_{z, c}^{1, t} / w_{t}^{1}=1-T_{t}^{\prime}\left(w_{t}^{1} l_{t}^{1}\right)$ and rearranging, we obtain equation (19) for the low-ability type. The marginal labor income tax rate for the high-ability type can be derived in a similar way.

\section{The Marginal Capital Income Tax Rates}

Let us consider the marginal capital income tax rate of the low-ability type. By combining equations (A2) and (A3), we obtain

$$
\operatorname{MRS}_{c, x}^{1, t}\left[\lambda_{t} \hat{u}_{t, x}^{2}+\gamma_{t+1} n_{t}^{1}-\frac{n_{t}^{1}}{N_{t+1}} \frac{\partial \mathcal{L}}{\partial \bar{c}_{t+1}}\right]=\lambda_{t} \hat{u}_{t, c}^{2}+\gamma_{t} n_{t}^{1}-\frac{n_{t}^{1}}{N_{t}} \frac{\partial \mathcal{L}}{\partial \overline{\mathrm{c}}_{\mathrm{t}}} .
$$

We then use equations (7) and (A7) to derive $M R S_{c, x}^{1, t}=1+r_{t+1}-r_{t+1} \Phi_{t+1}^{\prime}\left(s_{t}^{1} r_{t+1}\right)$ and $\gamma_{t}=\gamma_{t+1}\left[1+r_{t+1}\right]$, respectively. Substituting into equation (A17) and rearranging, we obtain equation (20). Equation (21) can be derived in a similar way.

Substituting equation (16), for period $t$ and period $t+1$, into equation (20) and (21), we obtain

$$
\Phi_{t+1}^{\prime}\left(s_{t}^{i} r_{t+1}\right)=\delta_{t}^{i}+\frac{\gamma_{t}}{\gamma_{t+1}} \frac{1}{r_{t+1}} \frac{\bar{\alpha}_{t}-\Gamma_{t}}{1-\bar{\alpha}_{t}}-\frac{1+r_{t+1}}{r_{t+1}} \frac{\bar{\alpha}_{t+1}-\Gamma_{t+1}}{1-\Gamma_{t+1}}+\Phi_{t+1}^{\prime}\left(s_{t}^{i} r_{t+1}\right) \frac{\bar{\alpha}_{t+1}-\Gamma_{t+1}}{1-\Gamma_{t+1}}
$$

for $i=1$, 2, where we have used the short notations $\delta_{t}^{1}$ and $\delta_{t}^{2}$ as defined earlier. Now, using $M R S_{c, x}^{i, t}=1+r_{t+1}-r_{t+1} \Phi_{t+1}^{\prime}\left(s_{t}^{i} r_{t+1}\right)$ together with $1+r_{t+1}=\gamma_{t} / \gamma_{t+1}$ in equation (A18) and rearranging, we obtain equation (22).

The proof of Corollary 1 follows from acknowledging that the mimicker and the low-ability type differ only with respect to preferences and the use of leisure. Given the separability assumption and that consumers share a common sub-utility function $f_{t}(\cdot)$, it follows that $M R S_{c, x}^{1, t}=M \hat{R} S_{c, x}^{2, t}$, which implies Corollary 1.

\section{Results of the case with comparisons within-generations; subsection 5.1}

\section{First-order conditions and positionality effects}

The first-order conditions for $l_{t}^{1}, l_{t}^{2}$, and $K_{t+1}$ are the same as before, whereas the optimality conditions for $c_{t}^{1}, x_{t+1}^{1}, c_{t}^{2}$, and $x_{t+1}^{2}$ are given by 
(A19)

$$
\begin{aligned}
& \frac{\partial W}{\partial\left(n_{t}^{1} U_{t}^{1}\right)} n_{t}^{1} u_{t, c}^{1}-\lambda_{t} \hat{u}_{t, c}^{2}-\gamma_{t} n_{t}^{1}+\frac{n_{t}^{1}}{n_{t}} \frac{\partial \mathcal{L}}{\partial \bar{c}_{t, t}}=0, \\
& \frac{\partial W}{\partial\left(n_{t}^{1} U_{t}^{1}\right)} n_{t}^{1} u_{t, x}^{1}-\lambda_{t} \hat{u}_{t, x}^{2}-\gamma_{t+1} n_{t}^{1}+\frac{n_{t}^{1}}{n_{t}} \frac{\partial \mathcal{L}}{\partial \bar{x}_{t+1, t}}=0, \\
& {\left[\frac{\partial W}{\partial\left(n_{t}^{2} U_{t}^{2}\right)} n_{t}^{2}+\lambda_{t}\right] u_{t, c}^{2}-\gamma_{t} n_{t}^{2}+\frac{n_{t}^{2}}{n_{t}} \frac{\partial \mathcal{L}}{\partial \bar{c}_{t, t}}=0,} \\
& {\left[\frac{\partial W}{\partial\left(n_{t}^{2} U_{t}^{2}\right)} n_{t}^{2}+\lambda_{t}\right] u_{t, x}^{2}-\gamma_{t+1} n_{t}^{2}+\frac{n_{t}^{2}}{n_{t}} \frac{\partial \mathcal{L}}{\partial \bar{x}_{t+1, t}}=0,}
\end{aligned}
$$

where $n_{t}=n_{t}^{1}+n_{t}^{2}$, and where the welfare effect of a change in the average consumption of the young people at time $t, \bar{c}_{t, t}$, can be written as

$$
\frac{\partial \mathcal{L}}{\partial \bar{c}_{t, t}}=\sum_{i=1}^{2} \frac{\partial W}{\partial\left(n_{t}^{i} U_{t}^{i}\right)} n_{t}^{i} u_{t, \bar{t}_{t, t}}^{i}+\lambda_{t}\left[u_{t, \bar{c}_{t, t}}^{2}-\hat{u}_{t, \bar{c}_{t, t}}^{2}\right],
$$

whereas the corresponding effect of a change in the average consumption of the old people at time $t, \bar{x}_{t, t-1}$, can be written as

$$
\frac{\partial \mathcal{L}}{\partial \bar{x}_{t, t-1}}=\sum_{i=1}^{2} \frac{\partial W}{\partial\left(n_{t-1}^{i} U_{t-1}^{i}\right)} n_{t-1}^{i} u_{t-1, \bar{x}_{t, t-1}}^{i}+\lambda_{t-1}\left[u_{t-1, \bar{x}_{t, t-1}}^{2}-\hat{u}_{t-1, \bar{x}_{t, t-1}}^{2}\right]
$$

From equation (25) we have that $u_{t, c}^{i}=v_{t, c}^{i}+v_{t, \Delta_{t}^{c c}}^{i}$ and $u_{t, \bar{c}_{t, t}}^{i}=-v_{t, \Delta_{t}^{c c}}^{i}$, which together with equation (26a) implies:

$$
u_{t, \bar{c}_{t, t}}^{i}=-\alpha_{t}^{i, c c} u_{t, c}^{i}
$$

whereas $u_{t, \bar{x}_{t+1, t}}^{i}=-v_{t, \Delta_{t+1}^{x x}}^{i}$ together with equation (26b) implies

$$
u_{t, \bar{x}_{t+1, t}^{i}}^{i}=-\alpha_{t+1}^{i, x x} u_{t, x}^{i}
$$

Substituting equations (A25) and (A26) into equation (A23) and (A24) we obtain,

$$
\begin{aligned}
& \frac{\partial \mathcal{L}}{\partial \bar{c}_{t, t}}=-\sum_{i=1}^{2} \frac{\partial W}{\partial\left(n_{t}^{i} U_{t}^{i}\right)} n_{t}^{i} \alpha_{t}^{i, c c} u_{t, c}^{i}-\lambda_{t}\left[\alpha_{t}^{2, c c} u_{t, c}^{2}-\hat{\alpha}_{t}^{2, c c} \hat{u}_{t, c}^{2}\right], \\
& \frac{\partial \mathcal{L}}{\partial \bar{x}_{t, t-1}}=-\sum_{i=1}^{2} \frac{\partial W}{\partial\left(n_{t-1}^{i} U_{t-1}^{i}\right)} n_{t-1}^{i} \alpha_{t}^{i, x x} u_{t-1, x}^{i}-\lambda_{t-1}\left[\alpha_{t}^{2, x x} u_{t-1, x}^{2}-\hat{\alpha}_{t}^{2, x x} \hat{u}_{t-1, x}^{2}\right] .
\end{aligned}
$$

Rewriting equations (A19)-(A22) in the same way as equations (A2), (A3), (A5), and (A6) were rewritten into equations (A11)-(A14), and substituting them into (A27) and (A28), implies equations (27a) and (27b). 
The optimal marginal labor income tax rates for the low and high-ability types are obtained by combining equation (6) with (A1) and (A19), and with (A4) and (A21), respectively:

$$
\begin{aligned}
& T_{t}^{\prime}\left(w_{t}^{1} l_{t}^{1}\right)=\frac{\lambda_{t}^{*}}{w_{t}^{1} n_{t}^{1}}\left[M R S_{z, c}^{1, t}-\phi M \hat{R} S_{z, c}^{2, t}\right]-\frac{M R S_{z, c}^{1, t}}{\gamma_{t} w_{t}^{1} n_{t}} \frac{\partial \mathcal{L}}{\partial \bar{c}_{t, t}}, \\
& T_{t}^{\prime}\left(w_{t}^{2} l_{t}^{2}\right)=-\frac{M R S_{z, c}^{2, t}}{\gamma_{t} w_{t}^{2} n_{t}} \frac{\partial \mathcal{L}}{\partial \bar{c}_{t, t}} .
\end{aligned}
$$

Substituting equation (27a) into equations (A29) and (A30), using that $M R S_{z, c}^{i, t} / w_{t}^{i}=1-T_{t}^{\prime}\left(w_{t}^{i} l_{t}^{i}\right)$ and rearranging then implies equation (28).

By combining equations (A19) and (A20), we obtain

$$
\operatorname{MRS}_{c, x}^{1, t}\left[\lambda_{t} \hat{u}_{t, x}^{2}+\gamma_{t+1} n_{t}^{1}-\frac{n_{t}^{1}}{n_{t+1}} \frac{\partial \mathcal{L}}{\partial \bar{x}_{t+1, t}}\right]=\lambda_{t} \hat{u}_{t, c}^{2}+\gamma_{t} n_{t}^{1}-\frac{n_{t}^{1}}{n_{t}} \frac{\partial \mathcal{L}}{\partial \bar{c}_{t, t}} .
$$

Substituting $M R S_{c, x}^{1, t}=1+r_{t+1}-r_{t+1} \Phi_{t+1}^{\prime}\left(s_{t}^{1} r_{t+1}\right)$ and $\gamma_{t}=\gamma_{t+1}\left[1+r_{t+1}\right]$, respectively, into equation (A31) and rearranging, we obtain equation (29). Equation (30) is derived correspondingly for the high-ability type. Substituting equations (27a) and (27b) into equations (29) and (30), and using that $M R S_{c, x}^{i, t}=1+r_{t+1}-r_{t+1} \Phi_{t+1}^{\prime}\left(s_{t}^{i} r_{t+1}\right)$ together with $1+r_{t+1}=\gamma_{t} / \gamma_{t+1}$, we obtain equation (31).

\section{Results of the case with upward comparisons; subsection 5.2}

First-order conditions and the positionality effect

The first-order conditions for $l_{t}^{1}, l_{t}^{2}$, and $K_{t+1}$ are again the same as before, whereas the optimality conditions for $c_{t}^{1}, x_{t+1}^{1}, c_{t}^{2}$, and $x_{t+1}^{2}$ are given by

$$
\begin{aligned}
& \frac{\partial W}{\partial\left(n_{t}^{1} U_{t}^{1}\right)} n_{t}^{1} u_{t, c}^{1}-\lambda_{t} \hat{u}_{t, c}^{2}-\gamma_{t} n_{t}^{1}=0, \\
& \frac{\partial W}{\partial\left(n_{t}^{1} U_{t}^{1}\right)} n_{t}^{1} u_{t, x}^{1}-\lambda_{t} \hat{u}_{t, x}^{2}-\gamma_{t+1} n_{t}^{1}=0, \\
& {\left[\frac{\partial W}{\partial\left(n_{t}^{2} U_{t}^{2}\right)} n_{t}^{2}+\lambda_{t}\right] u_{t, c}^{2}-\gamma_{t} n_{t}^{2}+\frac{n_{t}^{2}}{N_{t}} \frac{\partial \mathcal{L}}{\partial \bar{c}_{t}^{2}}=0,} \\
& {\left[\frac{\partial W}{\partial\left(n_{t}^{2} U_{t}^{2}\right)} n_{t}^{2}+\lambda_{t}\right] u_{t, x}^{2}-\gamma_{t+1} n_{t}^{2}+\frac{n_{t}^{2}}{N_{t}} \frac{\partial \mathcal{L}}{\partial \bar{c}_{t+1}^{2}}=0,}
\end{aligned}
$$


where the welfare effect of a change in the average consumption among the high-ability individuals at time $t, \bar{c}_{t}^{2}$, can be written as

$$
\begin{aligned}
& \frac{\partial \mathcal{L}}{\partial \bar{c}_{t}^{2}}=\sum_{i=1}^{2} \frac{\partial W}{\partial\left(n_{t-1}^{i} U_{t-1}^{i}\right)} n_{t-1}^{i} u_{t-1, \bar{c}_{t}^{2}}^{i}+\sum_{i=1}^{2} \frac{\partial W}{\partial\left(n_{t}^{i} U_{t}^{i}\right)} n_{t}^{i} u_{t, \bar{c}_{t}^{2}}^{i} \\
& +\lambda_{t-1}\left[u_{t-1, \bar{c}_{t}^{2}}^{2}-\hat{u}_{t-1, \bar{c}_{t}^{2}}^{2}\right]+\lambda_{t}\left[u_{t, \bar{c}_{t}^{2}}^{2}-\hat{u}_{t, \bar{c}_{t}^{2}}^{2}\right]
\end{aligned}
$$

From equation (32) we have $u_{t, c}^{i}=v_{t, c}^{i}+v_{t, \Delta_{t}^{2 c}}^{i}, \quad u_{t, \bar{c}_{t}}^{i}=-v_{t, \Delta_{t}^{2 c}}^{i}, \quad u_{t, x}^{i}=v_{t, x}^{i}+v_{t, \Delta_{t+1}^{2 x}}^{i}$, and $u_{t, \bar{c}_{t+1}}^{i}=-v_{t, \Delta_{t+1}^{2 x}}^{i}$, which (with corresponding expressions for the mimicker) imply that $u_{t, \bar{c}_{t}^{2}}^{i}=-\alpha_{t}^{i 2, c} u_{t, c}^{i}$ and $u_{t, \bar{c}_{t+1}^{2}}^{i}=-\alpha_{t+1}^{i 2, x} u_{t, x}^{i}$. These expressions substituted into equation (A36) imply

$$
\begin{aligned}
\frac{\partial \mathcal{L}}{\partial \bar{c}_{t}^{2}} & =-\sum_{i=1}^{2} \frac{\partial W}{\partial\left(n_{t-1}^{i} u_{t-1}^{i}\right)} n_{t-1}^{i} \alpha_{t}^{i 2, x} u_{t-1, x}^{i}-\sum_{i=1}^{2} \frac{\partial W}{\partial\left(n_{t}^{i} u_{t}^{i}\right)} n_{t}^{i} \alpha_{t}^{i 2, c} u_{t, c}^{i} \\
& -\lambda_{t-1}\left[\alpha_{t}^{22, x} u_{t-1, x}^{2}-\hat{\alpha}_{t}^{22, x} \hat{u}_{t-1, x}^{2}\right]-\lambda_{t}\left[\alpha_{t}^{22, c} u_{t, c}^{2}-\hat{\alpha}_{t}^{22, c} \hat{u}_{t, c}^{2}\right] .
\end{aligned}
$$

Rewriting equations (A32)-(A35) in the same way as equations (A2), (A3), (A5), and (A6) were rewritten into equations (A11)-(A14), and substituting them into (A37), implies

$$
\frac{\partial \mathcal{L}}{\partial \bar{c}_{t}^{2}}=-\frac{\bar{\alpha}_{t}^{2} \gamma_{t} N_{t}}{1-\bar{\alpha}_{t}^{22}}+\frac{1}{1-\bar{\alpha}_{t}^{22}}\left[\lambda_{t-1} \hat{u}_{t-1, x}^{2}\left[\hat{\alpha}_{t}^{22, x}-\alpha_{t}^{12, x}\right]+\lambda_{t} \hat{u}_{t, c}^{2}\left[\hat{\alpha}_{t}^{22, c}-\alpha_{t}^{12, c}\right]\right] \text {. }
$$

\section{The Marginal Labor and Capital Income Tax Rates}

The optimal marginal labor income tax rates for the low and high-ability types are obtained by combining equation (6) with (A1) and (A32), and with (A4) and (A34), respectively:

$$
\begin{aligned}
& T_{t}^{\prime}\left(w_{t}^{1} l_{t}^{1}\right)=\frac{\lambda_{t}^{*}}{w_{t}^{1} n_{t}^{1}}\left[M R S_{z, c}^{1, t}-\phi M \hat{R} S_{z, c}^{2, t}\right], \\
& T_{t}^{\prime}\left(w_{t}^{2} l_{t}^{2}\right)=-\frac{M R S_{z, c}^{2, t}}{\gamma_{t} w_{t}^{2} n_{t}} \frac{\partial \mathcal{L}}{\partial \bar{c}_{t}^{2}} .
\end{aligned}
$$

Substituting equation (A38) into equation (A40), using that $M R S_{z, c}^{2, t} / w_{t}^{2}=1-T_{t}^{\prime}\left(w_{t}^{2} l_{t}^{2}\right)$ and rearranging, then implies equation (34).

By combining equations (A32) and (A33), and (A34) and (A35), respectively, we obtain

$$
\operatorname{MRS}_{c, x}^{1, t}\left[\lambda_{t} \hat{u}_{t, x}^{2}+\gamma_{t+1} n_{t}^{1}\right]=\lambda_{t} \hat{u}_{t, c}^{2}+\gamma_{t} n_{t}^{1}
$$




$$
M R S_{c, x}^{2, t}\left[\gamma_{t+1} n_{t}^{2}-\frac{n_{t}^{2}}{N_{t}} \frac{\partial \mathcal{L}}{\partial \bar{c}_{t+1}^{2}}\right]=\gamma_{t} n_{t}^{2}-\frac{n_{t}^{2}}{N_{t}} \frac{\partial \mathcal{L}}{\partial \bar{c}_{t}^{2}} .
$$

Using that $M R S_{c, x}^{i, t}=1+r_{t+1}-r_{t+1} \Phi_{t+1}^{\prime}\left(s_{t}^{i} r_{t+1}\right)$ together with $\left[1+r_{t+1}\right]=\gamma_{t} / \gamma_{t+1}$ and substituting equation (A38) into equation (A42), we obtain

$$
\Phi_{t+1}^{\prime}\left(s_{t}^{1} r_{t+1}\right)=\frac{\lambda_{t} \hat{t}_{t, x}^{2}}{\gamma_{t+1} n_{t}^{1} r_{t+1}}\left[M R S_{c, x}^{1, t}-M \hat{R} S_{c, x}^{2, t}\right]
$$

and equation (35).

\section{References}

Abel, A. B., "Optimal Taxation When Consumers Have Endogenous Benchmark Levels of Consumption,” Review of Economic Studies 72 (2005), 1-19.

Akerlof, G. A, “Social Distance and Social Decisions,” Econometrica 65 (1997), 1005-1027.

Alpizar, F., F. Carlsson and O. Johansson-Stenman, "How Much Do We Care About Absolute versus Relative Income and Consumption?,” Journal of Economic Behavior and Organization 56 (2005), 405-421.

Aronsson, T. and O. Johansson-Stenman, "When the Joneses' Consumption Hurts: Optimal Public Good Provision and Nonlinear Income Taxation,” Journal of Public Economics 92 (2008a), 986-997.

Aronsson, T. and O. Johansson-Stenman, "Positional Concerns with Multiple Reference Points: Optimal Income Taxation and Public Goods in an OLG Model,”. Working Papers in Economics 304, Department of Economics, University of Gothenburg, 2008b.

Aronsson, T., T. Sjögren and T. Dalin, "Optimal Taxation and Redistribution in an OLG

Model with Unemployment," International Tax and Public Finance 16 (2009), 198218.

Arrow, K. and P. Dasgupta, “Conspicuous Consumption, Inconspicuous Leisure,” Economic Journal, in press,

Blomquist, S., "Interdependent Behavior and the Effect of Taxes," Journal of Public Economics 51 (1993), 211-218.

Boadway, R. and M. Keen, "Public Goods, Self-Selection and Optimal Income Taxation," International Economic Review 34 (1993), 463-78.

Boadway, R., M. Marchand and P. Pestieau, "Redistribution with Unobservable Bequests: A Case for Taxing Capital Income,” Scandinavian Journal of Economics 102 (2000), 253267. 
Bolton, G. E., and A. Ockenfels, "ERC: A Theory of Equity, Reciprocity and Competition,” American Economic Review 90 (2000), 166-193.

Boskin, M. J., and E. Sheshinski, “Individual Welfare Depends upon Relative Income,” Quarterly Journal of Economics 92 (1978), 589-601.

Bowles, S., and Y.-J. Park, "Inequality, Emulation, and Work Hours: Was Thorstein Veblen Right?,” Economic Journal 15 (2005), F397-F413.

Brekke, K.-A., and R. B. Howarth, Affluence, Well-Being and Environmental Quality, (Cheltenham: Edward Elgar 2002).

Brett, C. “A Note on Nonlinear Taxation in an Overlapping Generations Model,” mimeo, Department of Economics, University of Essex, 1997.

Carlsson, F., O. Johansson-Stenman and P. Martinsson, "Do You Enjoy Having More Than Others? Survey Evidence of Positional Goods,” Economica 74 (2007), 586-598.

Clark, A. E., P. Frijters and M. A. Shields, "Relative Income, Happiness and Utility: An Explanation for the Easterlin Paradox and Other Puzzles,” Journal of Economic Literature 46 (2008), 95-144.

Corneo, G., and O. Jeanne, "Conspicuous Consumption, Snobbism and Conformism," Journal of Public Economics 66 (1997), 55-71.

Corneo, G., and O. Jeanne, "Status, the Distribution of Wealth, and Growth," Scandinavian Journal of Economics 103 (2001), 283-293.

Duesenberry, J. S., Income, Saving and the Theory of Consumer Behavior. (Harvard Univeristy Press, Cambridge, MA, 1949).

Dupor, B. and W. F. Liu, “Jealousy and overconsumption,” American Economic Review 93 (2003), 423-428.

Easterlin, R.A., “Will Raising the Incomes of All Increase the Happiness of All?,” Journal of Economic Behavior and Organization 27 (1995), 35-47.

Easterlin, R.A., “Income and Happiness: Towards a Unified Theory,”Economic Journal 111 (2001), 465-484.

Ferrer-i-Carbonell, A., "Income and Well-being: An Empirical Analysis of the Comparison Income Effect,” Journal of Public Economics 89 (2005), 997-1019.

Fehr, E. and K. M. Schmidt, "A Theory of Fairness, Competition and Co-operation," Quarterly Journal of Economics 114 (1999), 817-868.

Frank, R. H., “The Demand for Unobservable and Other Nonpositional Goods,” American Economic Review 75 (1985), 101-16. 
Frank, R. H., Luxury Fever: Money and Happiness in an Era of Excess, (Princeton: Princeton University Press, 1999).

Frank, R. H., Falling Behind: How Rising Inequality Harms the Middle Class (Berkeley: University of California Press, 2007).

Frank, R. H., “Should Public Policy Respond to Positional Externalities?,” Journal of Public Economics 92 (2008), 1777-1786.

Frank, R. H. and R. M. Hutchens, "Wages, Seniority, and the Demand for Rising Consumption Profiles,” Journal of Economic Behavior and Organization 21 (1993), 251-76.

Hopkins, E. and T. Kornienko, "Running to Keep in the Same Place: Consumer Choice as a Game of Status,” American Economic Review 94 (2004), 1085-1107.

Ireland, N. J., “Optimal Income Tax in the Presence of Status Effects," Journal of Public Economics 81 (2001), 193-212.

Johansson-Stenman, O., F. Carlsson and D. Daruvala, “Measuring Future Grandparents' Preferences for Equality and Relative Standing,” Economic Journal 112 (2002), 362383.

Johansson-Stenman, O. and P. Martinsson, "Honestly, Why are You Driving a BMW?,” Journal of Economic Behavior and Organization 60, (2006), 129-146.

Keynes, J. M., “Economic Possibilities for Our Grandchildren,” (1930). Reprinted in Essays In Persuasion, 358-73. (New York: W. W. Norton, 1963).

Layard, R., “Human Satisfaction and Public Policy,” Economic Journal 90 (1980), 737-750.

Ljungqvist, L. and H. Uhlig, “Tax Policy and Aggregate Demand Management Under Catching Up with the Joneses,” American Economic Review 90 (2000), 356-366.

Loewenstein, G. F. and Sicherman, N., "Do workers prefer increasing wage profiles?,” Journal of Labor Economics 9 (1991), 67-84.

Luttmer, E. F. P., “Neighbors as Negatives: Relative Earnings and Well-Being,” Quarterly Journal of Economics 120 (2005), 963-1002.

McBride, M., "Relative-Income Effects on Subjective Well-Being in the Cross-Section," Journal of Economic Behavior \& Organization 45, (2001), 251-278.

Micheletto, L. "Optimal Nonlinear Redistributive Taxation and Public Good Provision in an Economy with Veblen Effects,” Working paper, Department of Economics, University of Milan (2008).

Ng, Y.-K., "Relative Income Effects and the Appropriate Level of Public Expenditure,” Oxford Economic Papers 39 (1987), 293-300. 
Ordover, J. E. and E. S. Phelps, "The Concept of Optimal Taxation in the Overlapping Generations Model of Capital and Wealth,” Journal of Public Economics 12 (1979), 126.

Oswald, A., “Altruism, Jealousy and the Theory of Optimal Non-Linear Taxation,” Journal of Public Economics 20 (1983), 77-87.

Pingle, M. and M. Mitchell, "What Motivates Positional Concerns for Income?,” Journal of Economic Psychology 23 (2002), 127-148.

Pirttilä, J. and M. Tuomala, “On Optimal Non-Linear Taxation and Public Good Provision in an Overlapping Generations Economy,” Journal of Public Economics 79 (2001), 485501.

Rayo, L. and G. S. Becker, “Evolutionary Efficiency and Happiness,” Journal of Political Economy 115 (2007), 302-337.

Runciman, W. G. Relative Deprivation and Social Justice, (Routledge and Kegan Paul, London, 1966).

Samuelson, L., “Information-Based Relative Consumption Effects,” Econometrica 72 (2004), 93-118.

Schor, J., The Overspent American (New York: Harper Perennial, 1998).

Solnick, S. and D. Hemenway, “Is More Always Better?: A Survey on Positional Concerns,” Journal of Economic Behavior and Organization 37 (1998), 373-383.

Solnick, S. and D. Hemenway, “Are Positional Concerns Stronger in Some Domains than in Others?,” American Economic Review, Papers and Proceedings 45 (2005), 147-151.

Stern, N. H., "Optimum Taxation with Errors in Administration," Journal of Public Economics 17 (1982), 181-211.

Stevenson, B. and J. Wolfers, "Economic Growth and Subjective Well-Being: Reassessing the Easterlin Paradox,” Brookings Papers on Economic Activity, Spring (2008), 1-87.

Stiglitz, J. E., "Self-Selection and Pareto Efficient Taxation,” Journal of Public Economics 17 (1982), 213-240.

Tuomala, M., Optimal Income Tax and Redistribution (Oxford: Clarendon Press, 1990).

Veblen, T. The Theory of the Leisure Class: An Economic Study in the Evolution of Institutions, (New York: Macmillan,1899).

Wendner, R. and L. H. Goulder, "Status Effects, Public Goods Provision, and the Excess Burden,” Journal of Public Economics 92 (2008), 1968-1985. 